\title{
Direct satellite observation of lightning-produced $\mathrm{NO}_{\mathrm{x}}$
}

\author{
S. Beirle ${ }^{1}$, H. Huntrieser ${ }^{2}$, and T. Wagner ${ }^{1}$ \\ ${ }^{1}$ Max-Planck-Institut für Chemie, Mainz, Germany \\ ${ }^{2}$ Institut für Physik der Atmosphäre, Deutsches Zentrum für Luft- und Raumfahrt (DLR), Oberpfaffenhofen, Germany
}

Received: 9 July 2010 - Published in Atmos. Chem. Phys. Discuss.: 2 August 2010

Revised: 11 November 2010 - Accepted: 18 November 2010 - Published: 24 November 2010

\begin{abstract}
Lightning is an important source of $\mathrm{NO}_{\mathrm{x}}$ in the free troposphere, especially in the tropics, with strong impact on ozone production. However, estimates of lightning $\mathrm{NO}_{\mathrm{x}}$ $\left(\mathrm{LNO}_{\mathrm{x}}\right)$ production efficiency $\left(\mathrm{LNO}_{\mathrm{x}}\right.$ per flash) are still quite uncertain.
\end{abstract}

In this study we present a systematic analysis of $\mathrm{NO}_{2}$ column densities from SCIAMACHY measurements over active thunderstorms, as detected by the World-Wide Lightning Location Network (WWLLN), where the WWLLN detection efficiency was estimated using the flash climatology of the satellite lightning sensors LIS/OTD. Only events with high lightning activity are considered, where corrected WWLLN flash rate densities inside the satellite pixel within the last hour are above $1 / \mathrm{km}^{2} / \mathrm{h}$. For typical SCIAMACHY ground pixels of $30 \times 60 \mathrm{~km}^{2}$, this threshold corresponds to 1800 flashes over the last hour, which, for literature estimates of lightning $\mathrm{NO}_{\mathrm{x}}$ production, should result in clearly enhanced $\mathrm{NO}_{2}$ column densities.

From 2004-2008, we find 287 coincidences of SCIAMACHY measurements and high WWLLN flash rate densities. For some of these events, a clear enhancement of column densities of $\mathrm{NO}_{2}$ could be observed, indeed. But overall, the measured column densities are below the expected values by more than one order of magnitude, and in most of the cases, no enhanced $\mathrm{NO}_{2}$ could be found at all.

Our results are in contradiction to the currently accepted range of $\mathrm{LNO}_{\mathrm{x}}$ production per flash of 15 (2$40) \times 10^{25} \mathrm{molec} / \mathrm{flash}$. This probably partly results from the specific conditions for the events under investigation, i.e. events of high lightning activity in the morning (local time) and mostly (for 162 out of 287 events) over ocean.

Within the detected coincidences, the highest $\mathrm{NO}_{2}$ column densities were observed around the US Eastcoast. This might

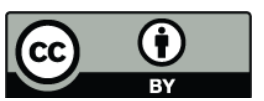

Correspondence to: S. Beirle

(steffen.beirle@mpic.de) be partly due to interference with ground sources of $\mathrm{NO}_{\mathrm{x}}$ being uplifted by the convective systems. However, it could also indicate that flashes in this region are particularly productive.

We conclude that current estimates of $\mathrm{LNO}_{\mathrm{x}}$ production might be biased high for two reasons. First, we observe a high variability of $\mathrm{NO}_{2}$ for coincident lightning events. This high variability can easily cause a publication bias, since studies reporting on high $\mathrm{NO}_{\mathrm{x}}$ production have likely been published, while studies finding no or low amounts of $\mathrm{NO}_{\mathrm{x}}$ might have been rejected as errorneous or not significant. Second, many estimates of $\mathrm{LNO}_{\mathrm{x}}$ production in literature have been performed over the US, which is probably not representative for global lightning.

\section{Introduction}

Nitrogen oxides ( $\mathrm{NO}$ and $\mathrm{NO}_{2}$, summarized as $\mathrm{NO}_{\mathrm{x}}$ ) play an important role in atmospheric chemistry by driving ozone formation and influencing the $\mathrm{OH}$ concentration. Lightning constitutes an important natural source of $\mathrm{NO}_{\mathrm{x}}$, hereafter denoted as Lightning $\mathrm{NO}_{\mathrm{x}}\left(\mathrm{LNO}_{\mathrm{x}}\right)$. $\mathrm{LNO}_{\mathrm{x}}$ is directly produceded in the upper troposphere where background levels of $\mathrm{NO}_{\mathrm{x}}$ are generally low and the lifetime of $\mathrm{NO}_{\mathrm{x}}$ is of the order of a few days, i.e. several times longer than for the boundary layer $(\approx$ hours $)$. Hence its impact on ozone production and oxidizing capacity is quite high (e.g., Labrador et al., 2005), compared to its fraction of total $\mathrm{NO}_{\mathrm{x}}$ production. However, estimates of the total annual $\mathrm{NO}_{\mathrm{x}}$ release by lightning are still uncertain, and literature results differ significantly, though they seem to be converging on the range of 2-8 $\mathrm{Tg} \mathrm{N} \mathrm{yr}^{-1}$ (Schumann and Huntrieser, 2007, and references therein).

Published by Copernicus Publications on behalf of the European Geosciences Union. 
In recent years, satellite measurements of $\mathrm{NO}_{2}$ have become available, which have provided a valuable dataset of tropospheric $\mathrm{NO}_{\mathrm{x}}$ with global coverage. Nadir-viewing UVVis satellites like GOME(1\&2), SCIAMACHY, or OMI, allow the retrieval of total slant column densities (SCDs), i.e. integrated concentrations along the effective light path, of several atmospheric trace gases. For $\mathrm{NO}_{2}$, the retrieval of tropospheric SCDs (TSCDs) requires the subtraction of the stratospheric column. Tropospheric vertical column densities (TVCDs), i.e. vertically integrated concentrations, are obtained by consideration of radiative transfer, involving information of ground albedo, aerosols and clouds, and the $\mathrm{NO}_{2}$ vertical profile. Tropospheric $\mathrm{NO}_{2}$ data from satellite has been successfully used for the investigation of $\mathrm{NO}_{\mathrm{x}}$ sources and chemistry in many studies (see e.g. Wagner, 2008; Martin et al., 2008, and references therein).

Several studies have also investigated and quantified $\mathrm{LNO}_{\mathrm{x}}$ using satellite $\mathrm{NO}_{2}$ observations. Beirle et al. (2004) found a correlation of flash counts from the Lightning Imaging Sensor (LIS) with monthly mean $\mathrm{NO}_{2}$ TSCDs from GOME over Australia, and estimated the mean $\mathrm{LNO}_{\mathrm{x}}$ production as $2.8(0.8-14) \mathrm{Tg} \mathrm{N} \mathrm{yr}^{-1}$. Boersma et al. (2005) reported on an increase of mean $\mathrm{NO}_{2}$ TVCDs over high convective clouds, and estimated the mean $\mathrm{LNO}_{\mathrm{x}}$ production as 1.1-6.4 $\mathrm{Tg} \mathrm{N} \mathrm{yr}^{-1}$ from correlations of $\mathrm{NO}_{2}$ TVCDs with parameterized flash rates. Martin et al. (2007) constrain the mean annual $\mathrm{LNO}_{\mathrm{x}}$ production to $6(4-8) \mathrm{Tg} \mathrm{N}$ by comparing satellite observations of $\mathrm{NO}_{2}, \mathrm{O}_{3}$ and $\mathrm{HNO}_{3}$ to a global chemical transport model. (Even the chemistry of the middle atmosphere is affected by lightning as has been shown by Arnone et al. (2008) who report on enhancements of $\mathrm{NO}_{2}$ from MIPAS of about $10 \%$ around the stratopause due to sprites.)

These approaches consider mean $\mathrm{NO}_{2}$ column densities for time periods of months to years. As lightning activity over continents peaks in the late afternoon, whereas current UV/vis satellite instruments measure $\mathrm{NO}_{2}$ in the morning (GOME, GOME2, SCIAMACHY) or shortly after noon (OMI), the potentially present $\mathrm{LNO}_{\mathrm{x}}$ is - to large part - aged. Consequently, spatial patterns of the $\mathrm{LNO}_{\mathrm{x}}$ produced by individual thunderstorms are lost, and the averaged $\mathrm{NO}_{2}$ enhancements are smeared out, and generally low. Thus, the impact of systematic errors within the retrieval is quite high. Especially uncertainties of the estimation of stratospheric column densities of the order of $0.5 \times 10^{15} \mathrm{molec} / \mathrm{cm}^{2}$ (Boersma et al., 2004) can strongly bias spatial averages over clean regions. Also spectral interferences of ground absorption features with the $\mathrm{NO}_{2}$ crosssection can lead to biased SCDs of the same order of magnitude (Beirle et al., 2010). Finally, to estimate the $\mathrm{NO}_{\mathrm{x}}$ production from mean $\mathrm{NO}_{2} \mathrm{VCDs}$, information on the $\mathrm{NO}_{\mathrm{x}}$ lifetime is required (or a chemical model has to be involved), which is also uncertain and, as a further complication, strongly height dependent. These difficulties can be overcome by investigating direct observations of freshly pro- duced $\mathrm{LNO}_{\mathrm{x}}$ over active thunderstorm: Beirle et al. (2006) analyzed a mesoscale convective system in the Gulf of Mexico in August 2000, which coincides with the GOME overpass in space and time. Individual GOME TSCDs are up to $10 \times 10^{15} \mathrm{molec} / \mathrm{cm}^{2}$. By roughly estimating the satellite's sensitivity for $\mathrm{NO}_{2}$ in cumulonimbus clouds, and relating the observed $\mathrm{NO}_{2}$ TSCDs to flashes detected by the US National Lightning Detection Network NLDN, a mean $\mathrm{LNO}_{\mathrm{x}}$ production of 90 (32-240) mol/flash, corresponding to 5.4(1.9$14.5) \times 10^{25} \mathrm{molec} /$ flash, was derived. Note that for this estimate it was assumed that the enhanced $\mathrm{NO}_{2}$ TSCD is completely due to lightning. In case of contributions of anthropogenic outflow from the US, the estimated $\mathrm{LNO}_{\mathrm{x}}$ production would be even lower. Bucsela et al. (2010) analyzed $\mathrm{OMI} \mathrm{NO}_{2}$ TVCDs within the TC4 campaign around Costa Rica and report on four days with lightning-related enhancements of OMI $\mathrm{NO}_{2}$ TVCDs. Involving in-situ $\mathrm{NO}_{2}$ profile measurements from the DC- 8 aircraft missions, and flash counts from lightning networks, they estimate $\mathrm{LNO}_{\mathrm{x}}$ production per flash in the range of $\approx 100-250 \mathrm{~mol} /$ flash, which corresponds to $6-15 \times 10^{25} \mathrm{molec} / \mathrm{flash}$.

For such direct observations, which generally imply satellite measurements under cloudy conditions, the aspect of the sensitivity is particularly important for quantitative analyses. The sensitivity of satellite observations can be expressed by the air mass factor (AMF) defined as the ratio of slant- to vertical column densities. Hild et al. (2002) analyzed AMFs for $\mathrm{NO}_{2}$ for cumulonimbus clouds, and found high sensitivity for $\mathrm{NO}_{2}$ at the cloud top, decreasing (approximately linear) to almost zero at the cloud bottom. Beirle et al. (2009) calculated $\mathrm{NO}_{2}$ AMFs for an ensemble of lightning scenarios from a cloud-resolving model, and in particular established a link between the measured $\mathrm{NO}_{2}$ TSCD to the actual $\mathrm{NO}_{\mathrm{x}}$ TVCD by considering the height-dependent $\mathrm{NO}_{\mathrm{x}}$ partitioning. Since the $\mathrm{NO}_{2} / \mathrm{NO}_{\mathrm{x}}$ ratio decreases with altitude due to decreasing temperatures and increasing actinic flux, the sensitivity for $\mathrm{NO}_{\mathrm{x}}$, in contrast to the box-AMFs for $\mathrm{NO}_{2}$, is not highest at the cloud top, but instead in the middle of the cloud. As result from Beirle et al. (2009), an overall quite high sensitivity of satellite observations for $\mathrm{LNO}_{\mathrm{x}}$ was determined. This leads to the straightforward expectation that events of high lightning activity, which will be defined quantitatively in Sect. 2.4, should produce an amount of $\mathrm{LNO}_{\mathrm{x}}$ that would result in enhanced $\mathrm{NO}_{2}$ TSCDs clearly detectable from space.

In this study, we make use of the global dataset of SCIAMACHY $\mathrm{NO}_{2}$ TSCDs, combined with global lightning data provided by WWLLN, to systematically search for events of high lightning activity and check our current understanding of $\mathrm{LNO}_{\mathrm{x}}$ production. In addition, the global perspective though limited by the low detection efficiency of WWLLN in some regions, and the restriction of SCIAMACHY to morning time - in principle allows to investigate possible systematic differences in regional $\mathrm{LNO}_{\mathrm{x}}$ productivity. 
Table 1. List of acronyms and symbols used in this study.

\begin{tabular}{lll}
\hline Symbol & Acronym & Explanation \\
\hline & LIS & Lightning imaging sensor \\
& OTD & Optical transient detector \\
& SCIAMACHY & $\begin{array}{l}\text { Scanning Imaging Absorption spectroMeter } \\
\text { for Atmospheric CHartographY }\end{array}$ \\
& TMI & TRMM microwave imager \\
& TRMM & Tropical rainfall measuring mission \\
& WWLLN & World Wide Lightning Location Network \\
& & Cloud-to-ground flash \\
& CG & Intra-cloud \\
& IC & Polarization-corrected temperature \\
& PCT & Tropospheric slant column density \\
$S$ & TSCD & Tropospheric vertical column density \\
$V$ & TVCD & Air Mass Factor \\
& AMF & \\
$E$ & & Sensitivity (see Eq. 1) \\
$F$ & FRD & Flash rate density \\
$D$ & DE & Detection efficiency \\
& PE & Production efficiency (LNO \\
& &
\end{tabular}

\section{Data and methods}

We perform a systematic analysis of $\mathrm{NO}_{2}$ column densities during and shortly after events of high lightning activity. $\mathrm{NO}_{2}$ data is derived from the SCIAMACHY instrument (Sect. 2.1), where the specific viewing conditions during thunderstorms and their impact on the sensitivity of satellite measurements is taken into account (Sect. 2.2). Lightning information is taken from the World-Wide Lightning Location Network (WWLLN, Sect. 2.3), which provides global and continuous lightning information. For quantitative interpretation of the WWLLN flash counts, the WWLLN detection efficiency (DE) is estimated using the flash climatology derived from LIS/OTD satellite measurements. In Sect. 2.4, the definition for "high" lightning activity is given. Finally, in Sect. 2.5, the observed $\mathrm{NO}_{2}$ TSCDs are set in relation to the number of WWLLN flashes, and the $\mathrm{LNO}_{\mathrm{x}}$ production efficiency is derived for each event.

To assist the reader, Table 1 gives an overview of the acronyms and symbols used in this study.

\subsection{SCIAMACHY $\mathrm{NO}_{2}$ column densities}

The Scanning Imaging Absorption spectroMeter for Atmospheric CHartographY, SCIAMACHY (Bovensmann et al., 1999), was launched onboard the ESA satellite ENVISAT in March 2002. ENVISAT orbits the Earth in a sunsynchronous orbit with a local equator crossing time of about 10:00 a.m. in descending node.

SCIAMACHY measures Earthshine spectra from the UV to the NIR with a spectral resolution of $0.22-1.48 \mathrm{~nm}$. In nadir geometry, the instrument performs an acrosstrack scan of about $\pm 32^{\circ}$, equivalent to a swath-width of
$960 \mathrm{~km}$. The footprint of a single nadir observation is typically $30 \times 60 \mathrm{~km}^{2}$. Global cover of nadir measurements is achieved after 6 days.

Total SCDs of $\mathrm{NO}_{2}$ are derived from SCIAMACHY nadir spectra using Differential Optical Absorption Spectroscopy DOAS (Platt and Stutz, 2008). Cross-sections of $\mathrm{O}_{3}, \mathrm{NO}_{2}$ (at $220 \mathrm{~K}$ ), $\mathrm{O}_{4}, \mathrm{H}_{2} \mathrm{O}$ and $\mathrm{CHOCHO}$ are fitted in the spectral range $430.8-459.5 \mathrm{~nm}$. In addition, Ring spectra, accounting for inelastic scattering in the atmosphere (rotational Raman) as well as in liquid water (vibrational Raman), an absorption cross-section of liquid water, and a polynomial of degree 5 are included in the fit procedure. A daily solar measurement is used as Fraunhofer reference spectrum. The fit error of $\mathrm{NO}_{2}$ SCDs is below $0.5 \times 10^{15} \mathrm{molec} / \mathrm{cm}^{2}$.

The stratospheric fraction of total SCDs as function of latitude is estimated in a reference sector over the remote Pacific. Longitudinal variations of the stratospheric field, which occur especially in cases of asymmetric polar vortices, are corrected using SCIAMACHY limb observations as described in Beirle et al. (2010). After substracting the estimated stratospheric field from total SCDs, tropospheric SCDs (TSCDs) of $\mathrm{NO}_{2}$ are derived. The uncertainty of the stratospheric estimation (in terms of SCDs) is of the order of typically 0.5 to $1 \times 10^{15} \mathrm{molec} / \mathrm{cm}^{2}$ for low and midlatitudes (see Fig. 6c in Beirle et al., 2010).

\subsection{Sensitivity of satellite observations for freshly produced $\mathrm{LNO}_{\mathrm{x}}$}

For a quantitative interpretation of $\mathrm{NO}_{2}$ TSCDs for lightning conditions, the extreme viewing conditions under $\mathrm{cu}-$ mulonimbus clouds have to be considered. For this purpose, Beirle et al. (2009) determined the "sensitivity" $E$, defined as ratio of $\mathrm{NO}_{2}$ TSCD (i.e. the $\mathrm{NO}_{2} \mathrm{SCD}$ observed from space after stratospheric correction) and the TVCD of $\mathrm{NO}_{\mathrm{x}}$ (i.e. the vertically integrated $\mathrm{NO}_{\mathrm{x}}$ column, which directly results from the totally released $\mathrm{LNO}_{\mathrm{x}}$ ):

$E:=S_{\mathrm{NO}_{2}} / V_{\mathrm{NO}_{\mathrm{x}}}$

This is a modification of the "classical" AMF description, which is necessary to account for the height-dependencies of both, the $\mathrm{NO}_{2}$ sensitivity (or box-AMF) and the $\mathrm{NO}_{2} / \mathrm{NO}_{\mathrm{x}}$ partitioning simultaneously. In Beirle et al. (2009), values for $S_{\mathrm{NO}_{2}}$, and thus $E$, were calculated using profiles of $\mathrm{NO}_{2}$, $\mathrm{NO}_{\mathrm{x}}$, and hydrometeors from a cloud-resolving chemistry model for a simulation of a one week thunderstorm episode in the TOGA COARE/CEPEX region, combined with a radiative transfer model.

The $\mathrm{NO}_{2} / \mathrm{NO}_{\mathrm{x}}$ ratio at the ground is about 0.7 (cloud free) up to 1 (clouded). It decreases approximately linearly with altitude down to values below 0.1 in the upper troposphere due to the high actinic flux and the low temperatures. BoxAMFs for $\mathrm{NO}_{2}$ are almost zero below a cloud, and reach values of more than 4 at the top of a cb cloud due to multiple scattering (compare Hild et al., 2002). 
As a consequence of these opposite height dependencies of the $\mathrm{NO}_{2} / \mathrm{NO}_{\mathrm{x}}$ ratio and the $\mathrm{NO}_{2}$ box-AMF, the sensitivity $E$ of satellite observations for $\mathrm{LNO}_{\mathrm{x}}$ is

- Low $(<0.1)$ at the cloud top and above: box-AMFs for $\mathrm{NO}_{2}$ are high, indeed, but there is almost no $\mathrm{NO}_{2}$ to be seen due to the low $\left[\mathrm{NO}_{2}\right] /\left[\mathrm{NO}_{\mathrm{x}}\right]$ ratio $<0.1$.

- Maximum $(\approx 1)$ in the cloud middle: here, $\mathrm{NO}_{2}$ boxAMFs are still high $(\approx 2)$, and there is enough $\mathrm{NO}_{\mathrm{x}}$ present in form of $\mathrm{NO}_{2}$ to be detected from space.

- Decreasing towards the cloud bottom, due to the decrease in $\mathrm{NO}_{2}$ box-AMFs.

- Almost zero below the cloud due to the cloud shielding.

For the simulated $\mathrm{LNO}_{\mathrm{x}}$ profiles, Beirle et al. (2009) find a mean sensitivity $E$ of 0.46 with a standard deviation of 0.09 . I.e., for a true $\mathrm{LNO}_{\mathrm{x}} \mathrm{TVCD}$ of $1 \times 10^{15} \mathrm{molec} / \mathrm{cm}^{2}$, it is expected to observe a NO $\mathrm{NSCD}_{2}$ of $0.46 \times 10^{15} \mathrm{molec} / \mathrm{cm}^{2}$ from satellite. Remarkedly, the values for $E$ are almost independent on cloud optical thickness, i.e. they are valid for the core, the anvil, and the outflow of a thunderstorm likewise. This is a consequence of the effects of clouds on both, the $\left[\mathrm{NO}_{2}\right] /\left[\mathrm{NO}_{\mathrm{x}}\right]$ ratio and the $\mathrm{NO}_{2}$ box-AMF, combined with the different mean $\mathrm{NO}_{\mathrm{x}}$ profiles for core (almost homogeneous) and outflow (C-shape), within the model study.

In the following, we apply this estimate of $E=0.46$ for the transformation of measured $\mathrm{NO}_{2}$ TSCDs into $\mathrm{NO}_{\mathrm{x}}$ TVCDs.

\subsection{The WWLLN}

For the identification of satellite measurements of $\mathrm{NO}_{2}$ coinciding with (or shortly after) events of high lightning activity, continuous lightning data is required. This is provided by the ground-based WWLLN.

WWLLN started operation as global lightning location network in 2003 (Dowden et al., 2008). It consists of $\approx 20-30$ sensors around the world detecting "sferics" caused by lightning in the very low frequency (VLF) band (6 to $22 \mathrm{kHz}$ ). A lightning stroke is identified if a sferic is detected by at least 5 WWLLN stations, and localized using the time of group arrival (Dowden et al., 2002).

The detection efficiency (DE) of WWLLN depends e.g. on the flash type (cloud-to-ground vs. intra-cloud): WWLLN is primarily focussing on the detection of cloud-to-ground (CG) flashes with well-defined return stroke peak currents (Rodger et al., 2006). However, Jacobson et al., 2006, showed that WWLLN is also capable of detecting intra-cloud (IC) flashes with similar DE, as long as their peak current is sufficiently high.

WWLLN only detects strokes with peak currents above $\approx 10 \mathrm{kA}$, with increasing DE for peak currents up to $50 \mathrm{kA}$. Above this level, the DE is not increasing further (Jacobson et al., 2006; Rodger et al., 2006, 2009).
In addition, the DE varies regionally and temporally, depending on the number and spatial distribution of participating ground stations. Note that the DE increased from 2007 on by about $63 \%$ (relative) due to an algorithm upgrade (Rodger et al., 2009). This algorithm update was meanwhile also used to reprocess the complete WWLLN timeseries, but in this study, the older version was used.

In order to quantify the actual number of flashes, we estimate the WWLLN DE as function of time and place. For this purpose, calibrated global lightning information is needed, which is provided by the flash climatology from combined LIS/OTD measurements (LIS: Lightning Imaging Sensor; OTD: Optical Transient Detector). We thus relate annual mean WWLLN flash rate densities (FRD) $F_{\text {WWLLN }}^{\text {annual }}$, i.e. flashes per area and year, to the corresponding climato-

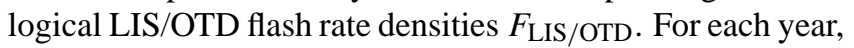
we define this ratio as "climatological" WWLLN DE $D_{\text {clim, }}$ given as function of place.

$D_{\text {clim }}:=\frac{F_{\mathrm{WWLLN}}^{\mathrm{annual}}}{F_{\mathrm{LIS} / \mathrm{OTD}}}$.

Note that we thereby (a) assume that the LIS/OTD climatology is "true" and (b) implicitely also correct for probable dependencies of WWLLN DE on flash type, since LIS and OTD are sensitive for CG and IC flashes likewise.

Regions with low LIS/OTD FRD $\left(<1 / \mathrm{km}^{2} /\right.$ year $)$ are skipped (i.e., $D_{\text {clim }}$ is not defined) to avoid small denominators.

For the quantification of flashes within the satellite pixel (see Sects. 2.4 and 2.5), we define a corrected WWLLN FRD $F_{\mathrm{WWLLN}}^{\mathrm{corr}}$ as

$F_{\mathrm{WWLLN}}^{\text {corr }}:=F_{\mathrm{WWLLN}} / D_{\text {clim. }}$.

To limit the upscaling of very low FRD, we only consider regions with $D_{\text {clim }}>1 \%$ in the following.

A detailed description of our procedure to estimate annual WWLLN DE, including maps of the resulting DEs, comparisons to literature estimates of $\mathrm{DE}$, a discussion on the diurnal cycle, and comparisons of individual WWLLN and LIS counts for selected individual events, are presented in Appendix A.

\subsection{Definition of "high" lightning activity}

In this study, we focus on SCIAMACHY $\mathrm{NO}_{2}$ measurements coinciding in time and space with high lightning activity, also simply denoted as "events" hereafter. The WWLLN flash counts within each satellite groundpixel are summed up over the last $60 \mathrm{~min}$ prior to the SCIAMACHY measurement. A coincidence is considered to be an "event" if the respective flash rate density $F_{\mathrm{WWLLN}}^{\mathrm{corr}}$, i.e. the sum of measured WWLLN flashes within the satellite pixel over the last $60 \mathrm{~min}$, scaled by $1 / D_{\text {clim }}$, is above $1 / \mathrm{km}^{2} / \mathrm{h}$. For a typical SCIAMACHY ground pixel of $30 \times 60 \mathrm{~km}^{2}$, this FRD corresponds to 1800 flashes within the last hour. 
Note that only flashes of the previous $60 \mathrm{~min}$ are counted; older flashes are not considered. Thus, the derived FRD is rather a lower bound for the actual number of flashes.

Events close to anthropogenic sources of $\mathrm{NO}_{\mathrm{x}}$ are potentially affected by ground $\mathrm{NO}_{\mathrm{x}}$ sources being uplifted by convective systems. Therefore, we define a "pollution mask" from the mean global distribution of $\mathrm{NO}_{2}$ TSCDs (i.e., regions where the annual mean SCIAMACHY TSCD is above $3 \times 10^{15} \mathrm{molec} / \mathrm{cm}^{2}$, plus a band of $500 \mathrm{~km}$ around, which basically masks polluted regions in continental and coastal US, Europe, and China) to limit the interference of anthropogenic $\mathrm{NO}_{\mathrm{x}}$. However, the latter may still occasionally occur outside the pollution mask in case of transport in the upper troposphere, and also $\mathrm{NO}_{\mathrm{x}}$ from biomass burning or soil emissions might interfere with $\mathrm{LNO}_{\mathrm{x}}$.

By our rigid definition of high lightning activity, however, we particularly focus on fresh $\mathrm{LNO}_{\mathrm{x}}$, where we can expect a direct spatial correlation of flash occurence and the $\mathrm{NO}_{2}$ signal.

\subsection{Relation of $\mathrm{NO}_{2}$ TSCD and WWLLN FRD}

Our goal is the clear identification of fresh lightning $\mathrm{NO}_{\mathrm{x}}$ in the $\mathrm{NO}_{2}$ TSCD of individual SCIAMACHY ground pixels, i.e. a well defined spatial and temporal match. The dimensions of a SCIAMACHY ground pixel are $30 \times 60 \mathrm{~km}^{2}$. This dimension corresponds approximately to a time interval of $1 \mathrm{~h}$, as wind speeds in the upper troposphere are of the order of $10-20 \mathrm{~m} / \mathrm{s}$ (compare Huntrieser et al., 2008, Table 4c therein). We thus consider flashes for $1 \mathrm{~h}$ back in time.

For the detected events, we relate the observed $\mathrm{NO}_{2}$ TSCDs to the respective WWLLN FRD. We therefore assume that $\mathrm{NO}_{\mathrm{x}}$ contributions from sources other than lightning are negligible, and that the loss of $\mathrm{LNO}_{\mathrm{x}}$ due to chemical transformations or outflow/dilution can be neglected within the considered time period of $\Delta T=1 \mathrm{~h}$ and for the area of a SCIAMACHY ground pixel of $30 \times 60 \mathrm{~km}^{2}$.

The $\mathrm{NO}_{\mathrm{x}}$ TVCD $V_{\mathrm{NO}_{\mathrm{x}}}$ due to lightning, i.e. the vertically integrated $\mathrm{LNO}_{\mathrm{x}}$ concentration, is then given as

$V_{\mathrm{NO}_{\mathrm{x}}}=F \times \Delta T \times P$

with $F$ being the flash rate density (flashes per time per area), i.e. $F \times \Delta T$ being a flash density (flashes per area), and $P$ the $\mathrm{LNO}_{\mathrm{x}}$ production per flash, denoted as "Production Efficiency" (PE) below. In the review of Schumann and Huntrieser (2007), the best estimate for $P$ is given as $15(2-40) \times 10^{25}$ molec $\left[\mathrm{NO}_{\mathrm{x}}\right] /$ flash (Table 21 therein; note that this estimate is based on several studies with different methodologies, and that for the contributing field measurements, different lightning detecting systems have been used). For our threshold FRD of $1 / \mathrm{km}^{2} / \mathrm{h}$ and the considered time period $\Delta T$ of $1 \mathrm{~h}$, we thus expect a $\mathrm{LNO}_{\mathrm{x}}$ TVCD of $15 \times 10^{15} \mathrm{molec} / \mathrm{cm}^{2}$. This corresponds to a $\mathrm{NO}_{2} \mathrm{TSCD}$ of $6.9 \times 10^{15} \mathrm{molec} / \mathrm{cm}^{2}$ (Eq. 1 with $E=0.46$ ). Such high
$\mathrm{NO}_{2}$ TSCDs are far above the DOAS fit noise, the uncertainty of the stratospheric estimation, or the $\mathrm{NO}_{2}$ background TSCDs for the considered "unpolluted" regions (typically about $0-1 \times 10^{15} \mathrm{molec} / \mathrm{cm}^{2}$ ), and would be clearly visible from space.

For each event, an individual PE $P_{\text {event }}$ can be estimated from the measured $\mathrm{NO}_{2} \mathrm{SCD}$ and the derived WWLLN FRD, using Eqs. (4), (1) and (3):

$P_{\text {event }}=\frac{V_{\mathrm{NO}_{\mathrm{x}}}}{F_{\text {event }} \times \Delta T}=\frac{S_{\mathrm{NO}_{2}} / E}{F_{\mathrm{WWLLN}}^{\mathrm{corr}} \times \Delta T}$.

Note that, by this definition, $P_{\text {event }}$ is overestimated whenever lightning activity more than $1 \mathrm{~h}$ ago can not be neglected.

\section{Results}

A systematic search of $\mathrm{NO}_{2}$ column measurements from SCIAMACHY for coincident lightning results in 287 events (as defined in Sect. 2.4) for the period 2004-2008. As expected, during (or shortly after) active thunderstorms, all satellite pixels for the detected events are cloud covered, with a mean FRESCO cloud fraction of 0.97 and a mean cloud height of $10.6 \mathrm{~km}$ (note that FRESCO cloud heights approximately correspond to the cloud middle (Wang et al., 2008), and all events are thus deep convective cases reaching the upper troposphere). Figure 1 shows the global distribution of the detected events. In addition, the derived Production Efficiency $P_{\text {event }}$ (Eq. 5) is color-coded. Some selected events, which are discussed in detail below, are labelled by their event-ID (see also Table 2).

The spatial distribution of the detected events (which is different from the general global distribution of lightning, compare Fig. A1 in Appendix A) is affected by $D_{\text {clim, the }}$ pollution mask, and morning-time flash characteristics. Most events are found around the Carribean Sea and in Indonesia/Australia, where WWLLDN DE is quite high (about 5\% up to $20 \%$ ), whereas only few events have been found in Central Africa, as a consequence of the DE threshold of $1 \%$. The pollution mask removes some events in the continental South-Eastern US, Southern Europe, and South-East Asia. As the diurnal cycle of continental lightning activity has a distinct minimum around 10:00 a.m. LT, while it is rather flat over oceans (compare Fig. A4 in Appendix A), many events (162) have been found over ocean.

Events with relative high PE (red dots in Fig. 1) agglomerate east from Florida and in the northern Gulf of Mexico, where already a clear coincidence of lightning and strongly enhanced $\mathrm{NO}_{2}$ TSCDs has been reported (Beirle et al., 2006). In contrast, in the northwest of Australia, where many events occured, values for $P_{\text {event }}$ are rather low (blue).

Figure 2 shows a scatterplot of $\mathrm{NO}_{2}$ TSCDs versus FRD for the detected events. The black line indicates the linear relation of Eq. (4) with a mean PE of 


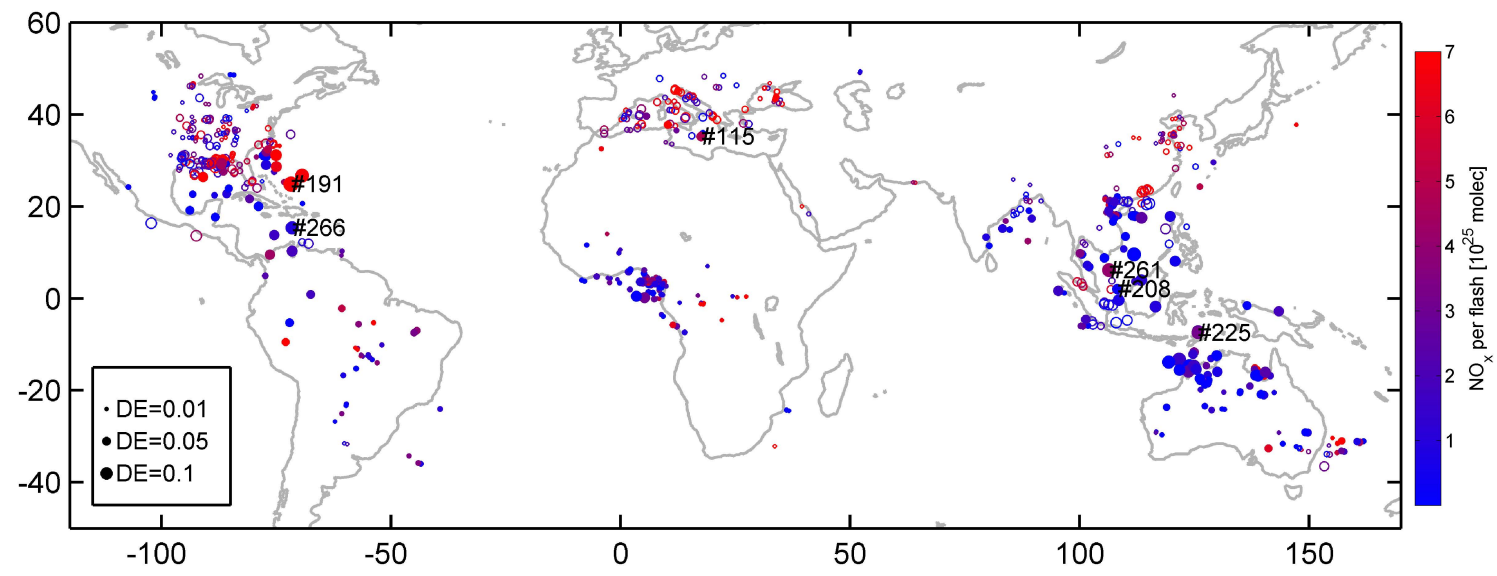

Fig. 1. Global map of events of high lightning activity coinciding with SCIAMACHY overpasses. The colors indicate the production efficiency, i.e. the $\mathrm{LNO}_{\mathrm{x}}$ production per flash $P_{\text {event }}$, for the assumptions made (see Sect. 2.4). The size of the circles indicates the estimated WWLLN DE $D_{\text {clim. }}$ Open circles indicate probably "polluted" events as defined by a pollution mask (see text). Some selected events, which are discussed in detail below, are labelled by their event ID.

Table 2. Selected events of high lightning activity (compare Figs. 3-5 and Sect. 2.4).

\begin{tabular}{|c|c|c|c|c|c|c|c|c|c|c|c|}
\hline $\begin{array}{l}\text { Cate- } \\
\text { gory }\end{array}$ & $\begin{array}{c}\text { Event } \\
\text { ID }\end{array}$ & Date & $\begin{array}{l}\text { FRD } \\
{\left[\frac{1}{\mathrm{~km}^{2} \mathrm{~h}}\right]}\end{array}$ & $\begin{array}{l}\mathrm{NO}_{2} \text { TSCD } \\
{\left[10^{15} \frac{\frac{\mathrm{molec}}{\mathrm{cm}^{2}}}{]}\right.}\end{array}$ & $\begin{array}{c}\text { Spatial } \\
\text { Corr. (R) }{ }^{1}\end{array}$ & $\begin{array}{c}\mathrm{PE} \\
{\left[10^{25} \frac{\mathrm{molec}}{\text { flash }}\right]}\end{array}$ & $\begin{array}{c}\text { WWLLN DE } \\
{[\%]}\end{array}$ & $\begin{array}{c}\text { Latitude } \\
\left.{ }^{\circ}{ }^{\circ}\right]\end{array}$ & $\begin{array}{c}\text { Longitude } \\
\left.\qquad{ }^{\circ}\right]\end{array}$ & $\begin{array}{c}\text { Cloud } \\
\text { fraction }^{2}\end{array}$ & $\begin{array}{c}\text { Cloud height }^{2} \\
{[\mathrm{~km}]}\end{array}$ \\
\hline A & $\# 115$ & 16 Oct 2006 & 2.9 & 4.6 & 0.04 & 3.5 & 5.5 & 35.3 & 17.5 & 1.0 & 10.9 \\
\hline $\mathrm{A}$ & \#191 & 12 May 2007 & 1.0 & 5.8 & 0.25 & 12.3 & 15.7 & 24.9 & -71.9 & 1.0 & 10.4 \\
\hline $\mathrm{C}$ & \#208 & 20 Aug 2007 & 5.8 & 0.5 & -0.03 & 0.2 & 7.2 & 2.1 & 108.2 & 1.0 & 12.1 \\
\hline B & $\# 225$ & 22 Nov 2007 & 2.2 & 2.4 & 0.52 & 2.3 & 10.7 & -7.4 & 125.7 & 1.0 & 12.6 \\
\hline B & \#261 & 13 May 2008 & 1.7 & 2.3 & 0.47 & 2.9 & 12.7 & 6.2 & 106.4 & 1.0 & 12.7 \\
\hline $\mathrm{C}$ & \#266 & $15 \mathrm{Jul} 2008$ & 1.0 & 0.3 & -0.06 & 0.7 & 11.3 & 15.4 & -71.6 & 1.0 & 11.2 \\
\hline
\end{tabular}

${ }^{1}$ The "spatial correlation" is defined as correlation coefficient $R$ between $\mathrm{NO}_{2}$ TSCDs and FRDs for the ground pixels within $\pm 2^{\circ}$ latitude and $\pm 3^{\circ}$ longitude of the respective event.

2 From FRESCO+ (Wang et al., 2008).

$P=15 \times 10^{25} \mathrm{molec} /$ flash and a sensitivity $E$ of 0.46 . From Fig. 2, we can conclude the following basic results of our systematic search for $\mathrm{LNO}_{\mathrm{x}}$ for events of high lightning activity:

1. The observed $\mathrm{NO}_{2}$ TSCDs are generally far below the expected range of about $5-10 \times 10^{15} \mathrm{molec} / \mathrm{cm}^{2}$ for a FRD of about 1 , and the derived PE is far lower than values given in literature for most events.

2. In contrast to our expectations, the events' $\mathrm{NO}_{2}$ TSCDs are not correlated to WWLLN flash rate densities $(R=$ $0.04)$. Therefore, we abandon to give an estimate of a "mean" PE in this study, which would be proportional to the slope of a - meaningless - linear fit to the data points in Fig. 2.

3. In some cases, a clear (spatial) coincidence of enhanced $\mathrm{NO}_{2}$ due to lightning could be found, similar to the case study of enhanced $\mathrm{NO}_{2}$ TSCDs observed from GOME in the Gulf of Mexico in August 2000 reported in Beirle et al., 2006. But for many events of high lightning ac- tivity, no enhanced $\mathrm{NO}_{2}$ could be observed at all. We find 136 events with $P_{\text {event }}<1 \times 10^{25}$ molec/flash.

Below we discuss some representative events, covering the range of observed PEs, in detail, and show spatial patterns of WWLLN flashes and $\mathrm{NO}_{2}$ TSCDs. We focus on events with high WWLLN detection efficiencies, to limit upscaling of WWLLN FRD with respective uncertainties. Consequently, most examples are taken after 2007, when WWLLN DE increased due to an improved algorithm (Rodger et al., 2009). Nevertheless, the general findings do not depend on $D_{\text {clim }}$, and events for lower DE are similarly variable.

We show illustrative examples for 3 general categories: (A) events with high $\mathrm{NO}_{2}$ TSCDs and relatively high PE, (B) events with medium PE, and (C) events with PE of almost 0 . For all examples, spatial patterns are displayed, showing the $\mathrm{NO}_{2} \mathrm{TSCD}$, the respective cloud fraction (FRESCO, Wang et al., 2008), and the detected WWLLN lightning strokes, where colour indicates the flash time with respect to the SCIAMACHY overpass. Table 2 lists the properties for the selected events. 


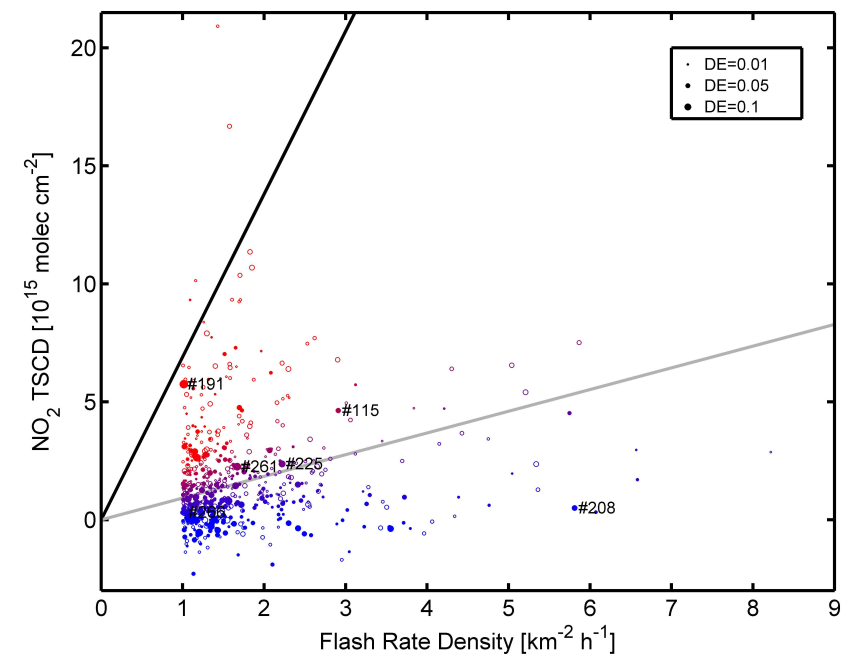

Fig. 2. $\mathrm{NO}_{2}$ TSCDs for the events of high lightning activity with FRD $>1 / \mathrm{km}^{2} / \mathrm{h}$. As in Fig. 1 , color codes $P_{\text {event }}$, and open circles indicate "polluted" events. The black line reflects the expectation (according to Eqs. 1 and 4) of $6.9 \times 10^{15} \mathrm{molec} / \mathrm{cm}^{2}$ per $1 / \mathrm{km}^{2} / \mathrm{h}$, or $P=15 \times 10^{15} \mathrm{molec} /$ flash. The grey line represents the lower bound $\left(P=2 \times 10^{15} \mathrm{molec} / \mathrm{flash}\right)$ given in Schumann and Huntrieser (2007).

\section{Category A: high $\mathrm{NO}_{2}$ TSCDs}

Figure 3 shows two examples of relatively high $\mathrm{NO}_{2} \mathrm{TSCDs}$ of $4.6 \times 10^{15} \mathrm{molec} / \mathrm{cm}^{2}$ (Event \#115, south of Italy) and $5.8 \times 10^{15} \mathrm{molec} / \mathrm{cm}^{2}$ (Event \#191, east of Florida) for the "events", i.e. the respective ground pixels with FRD $>1 / \mathrm{km}^{2} / \mathrm{h}$. Production Efficiencies $P_{\text {event }}$ are $3.5 \times 10^{25}$ (\#115) and $12.3 \times 10^{25}$ (\#191) molec/flash, respectively, almost reaching the best estimate given in Schumann and Huntrieser (2007).

However, in both cases, several neighbouring pixels (even hundreds of $\mathrm{km}$ afar) show TSCDs of more than $6 \times 10^{15} \mathrm{molec} / \mathrm{cm}^{2}$ as well, whereas the lightning activity detected by WWLLN is rather localized at the event, and the spatial correlation of $\mathrm{NO}_{2}$ TSCDs and FRD is rather poor $(R=0.04(\# 115) / 0.25(\# 191))$. The large plumes of enhanced $\mathrm{NO}_{2}$ thus indicate contributions from other $\mathrm{NO}_{\mathrm{x}}$ sources. In Appendix $\mathrm{C}$, we analyse these events in more detail and discuss how far these enhanced $\mathrm{NO}_{2}$ TSCDs can be explained by aged $\mathrm{LNO}_{\mathrm{x}}$ or continental outflow of anthropogenic $\mathrm{NO}_{\mathrm{x}}$.

\section{Category B: medium PE}

Figure 4 shows two illustrative examples for events with different lightning characteristics, where a $\mathrm{NO}_{2}$ response to lightning could be identified. Event \#261 (Malaysia) is a mesoscale convective system with more than $500 \mathrm{~km} \mathrm{ex-}$ tent. The respective $\mathrm{NO}_{2}$ TSCDs are slightly enhanced, and the maximum TSCD of $2.3 \times 10^{15} \mathrm{molec} / \mathrm{cm}^{2}$ coincides with the maximum FRD of $1.7 / \mathrm{km}^{2} / \mathrm{h}$. Spatial pat- terns of flashes and $\mathrm{NO}_{2}$ TSCDs correlate quite well $(R=$ 0.47), supporting the interpretation of the $\mathrm{NO}_{2}$ TSCDs to be due to lightning. However, the overall $\mathrm{NO}_{2}$ TSCD is rather small compared to our expectation, and $P_{\text {event }}$ is only $2.9 \times 10^{25} \mathrm{molec} /$ flash. Event \#225 (Timor) is an example for a very localized lightning event, where two neighbouring pixels exceed the FRD threshold of $1 / \mathrm{km}^{2} / \mathrm{h}$, but no lightning occurs outside. Again, $\mathrm{NO}_{2}$ is enhanced at the event (and only there; $R=0.52$ ), but TSCDs are only moderately enhanced $\left(2.4 \times 10^{15} \mathrm{molec} / \mathrm{cm}^{2}\right.$ maximum $)$, and $P_{\text {event }}$ is $2.3 \times 10^{25} \mathrm{molec} /$ flash. Note that such events are rather rare; only 11 events out of 287 have a spatial correlation coefficient of $>0.4$.

\section{Category C: “Zero" PE}

In contrast to these examples, where we can at least claim a spatial correlation of flashes and enhanced $\mathrm{NO}_{2}$, though the enhancement is lower than expected, Fig. 5 shows events with no detectable $\mathrm{NO}_{2}$ enhancement at all. For event \#266 (north of Venezuela), $\mathrm{NO}_{2}$ TSCDs are as few as $0.3 \times 10^{15} \mathrm{molec} / \mathrm{cm}^{2}$ for a FRD of $1 / \mathrm{km}^{2} / \mathrm{h}$; the neighbouring pixels show no indication of $\mathrm{LNO}_{\mathrm{x}}$ outflow neither. Similarly, for event \#208 (Malaysia), a very high FRD of 5.8 is observed, but $\mathrm{NO}_{2}$ TSCDs are below $0.5 \times 10^{15} \mathrm{molec} / \mathrm{cm}^{2}$ for the respective ground pixel, whereas expected TSCDs according to Eqs. (4) and (1) would be as high as $40 \times 10^{15} \mathrm{molec} / \mathrm{cm}^{2}$, which is two orders of magnitude higher. $P_{\text {event }}$ are $0.7 \times 10^{25}$ and $0.2 \times 10^{25} \mathrm{molec} /$ flash, respectively, for both events.

\section{Discussion}

We performed a systematic search for satellite $\mathrm{NO}_{2}$ observations coinciding with high lightning activity. According to literature values for PE, the high FRD over individual ground pixels would result in clearly enhanced TSCDs. But in contrast to that expectation, the observed $\mathrm{NO}_{2}$ TSCDs are generally far lower than expected, and show no correlation with WWLLN flash counts. Our findings are even more surprising given the fact that we do not consider flashes "older" than one hour and should thus estimate an upper bound of $\mathrm{LNO}_{\mathrm{x}}$ production, since our estimate of flash counts is a lower bound.

In the following, we discuss the different event categories for the examples shown in Sect. 3. We investigate how far our results might be affected by the assumptions and characteristics of

- the $\mathrm{NO}_{2}$ retrieval (Sect. 4.1),

- the satellites' sensitivity for lightning $\mathrm{NO}_{\mathrm{x}}$ (Sect. 4.2),

- the WWLLN DE (Sect. 4.3), 

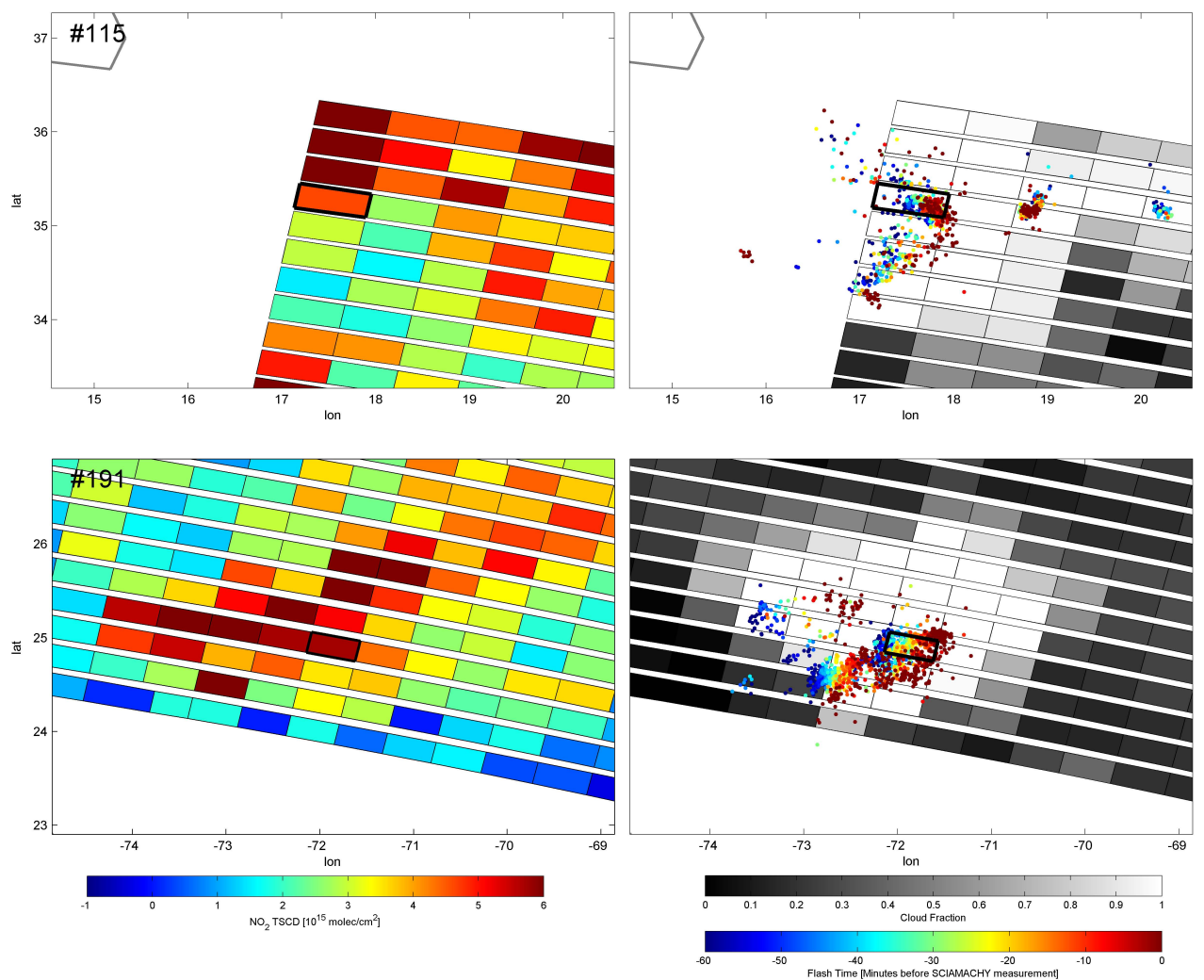

Fig. 3. Events \#115 on 16 October 2006 (top) and \#191 on 12 May 2007 (bottom). Left: $\mathrm{NO}_{2}$ TSCD. Right: FRESCO Cloud fraction (greyscale) and time of individual WWLLN flashes relative to the SCIAMACHY measurement (color).

- our definition of high lightning activity (Sect. 4.4),

- or our calculation of the PE (Sect. 4.5).

Finally, we discuss possible impacts of the observed high variability of $\mathrm{PE}$ on estimates of $\mathrm{LNO}_{\mathrm{x}}$ production in literature (Sect. 4.6), and evaluate possible reasons which might cause these differences in PE (Sect. 4.7).

\section{Category A: high $\mathrm{NO}_{2}$ TSCDs}

As shown in Fig. 1, most events of (relatively) high $P_{\text {event }}$ are observed in the Gulf of Mexico and east from Florida. This possibly indicates that PE is above average for the US, where deep convective updraft speeds are particularly high (Del Genio et al., 2007) and extreme precipitation is relatively frequent (Zipser et al., 2006). In fact, many reports of high PE in literature are based on measurements over the US, e.g. Hudman et al. (2007) $\left(P \approx 30 \times 10^{25}\right.$ molec/flash), Langford et al. (2004) ( $P \approx 58 \times 10^{25} \mathrm{molec} / \mathrm{CG}$ flash $)$ or Ott et al. (2010) ( $P \approx 22-42 \times 10^{25} \mathrm{molec} /$ flash, including also observations over Europe). Thus, one has to keep in mind that PE is likely regional dependent, and US estimates might not be representative globally.
For many of these high-PE events, like in event \#191 (see Fig. 3), the patterns of enhanced $\mathrm{NO}_{2}$ TSCDs cannot be explained by the flashes of the last hour. Thus, aged $\mathrm{LNO}_{\mathrm{x}}$, or the outflow of anthropogenic $\mathrm{NO}_{\mathrm{x}}$, lifted up by convection, probably contributes significantly to the observed $\mathrm{NO}_{2}$ TSCDs. The latter has to be taken into account when quantifying $\mathrm{LNO}_{\mathrm{x}}$ in the vicinity of "polluted" regions like the US eastcoast, where Bertram et al. (2007) estimated the fraction of air originating from the planetary boundary layer in convective outflow as $0.17 \pm 0.02$. I.e., convection alone can cause high $\mathrm{NO}_{2}$ TSCDs over polluted regions. This might partly explain the cluster of generally high PE found around the US For event \#191, there are indications for interference of anthropogenic $\mathrm{NO}_{\mathrm{x}}$ and possibly also biomass burning $\mathrm{NO}_{\mathrm{x}}$, as shown in Appendix C. For such events where additional contributions from aged $\mathrm{LNO}_{\mathrm{x}}$ or continental outflow of anthropogenic/biomass burning $\mathrm{NO}_{\mathrm{x}}$ are not negligible (but hard to quantify), the estimated $P_{\text {event }}$ are generally too high.

By our definition of events of high lightning activity and the calculation of $P_{\text {event }}$, we demand a spatial coincidence of lightning and $\mathrm{NO}_{2}$ signal. It has to be noted that if we would instead consider the averaged $\mathrm{NO}_{2}$ TSCD and the averaged FRD over a larger region of e.g. $300 \times 600 \mathrm{~km}^{2}$ (i.e. $10 \times 10$ SCIAMACHY pixels), we would end up with 

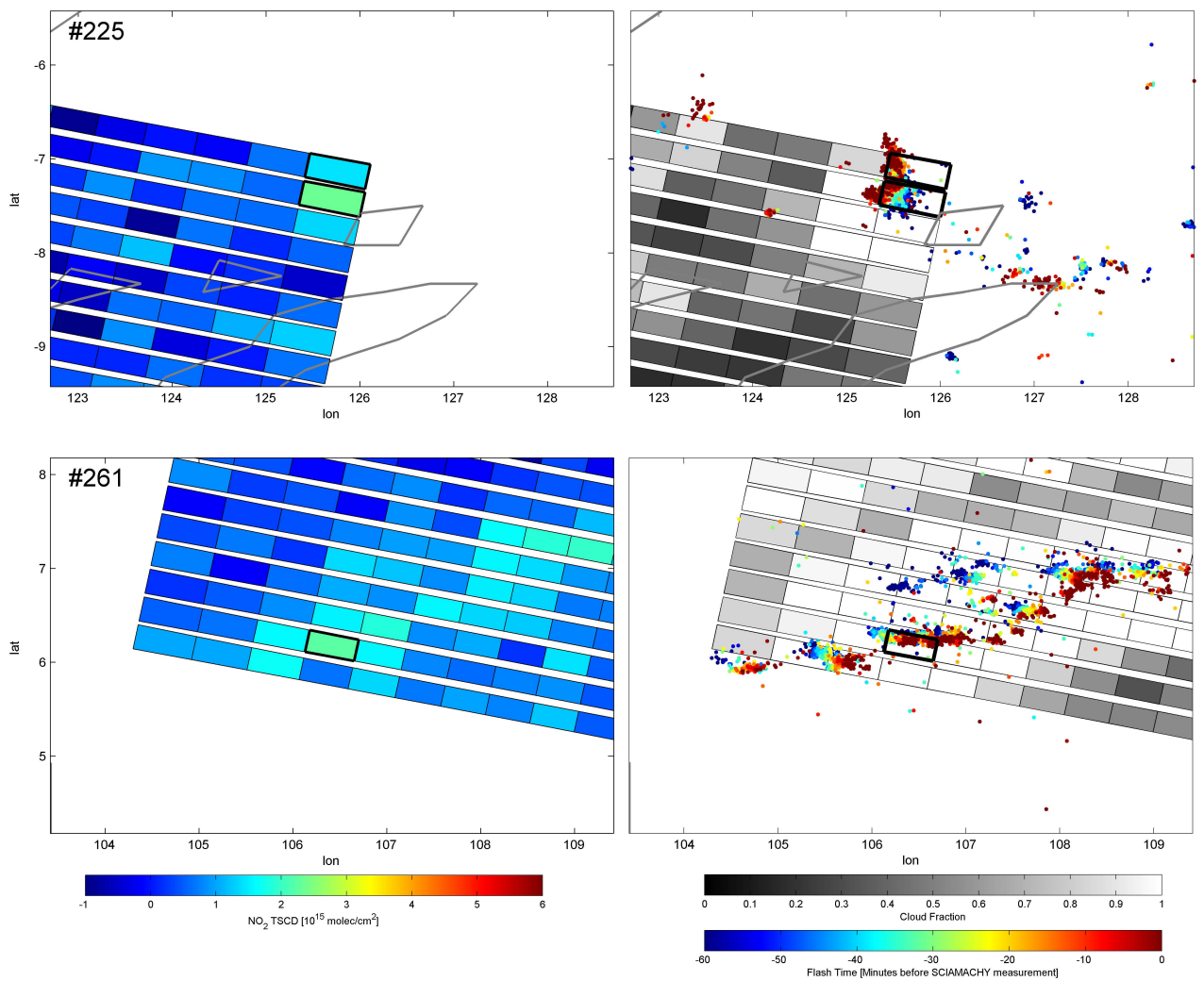

Fig. 4. Events \#225 on 22 November 2007 (top) and \#261 on 13 May 2008 (bottom). Left: $\mathrm{NO}_{2}$ TSCD. Right: FRESCO Cloud fraction (greyscale) and time of individual WWLLN flashes relative to the SCIAMACHY measurement (color).

a tremendously high PE of about $300 \times 10^{25} \mathrm{molec} /$ flash for event \#191. Even if we account for flashes over the last 10 flashes, PE would still be as high as $62 \times 10^{25} \mathrm{molec} / \mathrm{flash}$, despite the fact that large parts of the enhanced $\mathrm{NO}_{2}$ plume show no spatial correlation with the observed flashes. This underlines the importance of identifying enhanced $\mathrm{NO}_{2}$ TSCDs being due to lightning by demanding consistent spatial patterns of $\mathrm{NO}_{2}$ and FRD. We therefore analyze their relationship for individual satellite ground pixels instead of calculating large-scale spatial means (see also Sect. 4.5).

\section{Category B: medium $\boldsymbol{P}_{\text {event }}$}

In some cases, moderately enhanced $\mathrm{NO}_{2}$ TSCDs have been found which show consistent spatial patterns with WWLLN flashes (see Fig. 4). These examples demonstrate that, in some cases, it is actually possible to detect $\mathrm{LNO}_{\mathrm{x}}$ from space, based on a clear spatial correlation of flashes and enhanced $\mathrm{NO}_{2}$ TSCD. The values for $P_{\text {event }}$ of about 2$3 \times 10^{25} \mathrm{molec} /$ flash are lower than the best estimate given in Schumann and Huntrieser (2007), but are within the range of uncertainty of $2-40 \times 10^{25} \mathrm{molec} /$ flash. Note that a PE of $3 \times 10^{25} \mathrm{molec} /$ flash would correspond to a total annual flash production of about $1 \mathrm{Tg} \mathrm{N} \mathrm{yr}^{-1}$.

\section{Category C: "Zero" $P_{\text {event }}$}

The majority of events show no significantly enhanced $\mathrm{NO}_{2}$ TSCDs at all, also causing an overall correlation coefficient of about 0 between FRD and $\mathrm{NO}_{2}$ TSCD. The estimated values for $P_{\text {event }}$ are orders of magnitude below the range reported in literature. From the quantities listed in Table 2, or the spatial patterns of flashes, we could not find an indication for what makes these "zero"-events different from the other. E.g., PE is not correlated with FRESCO cloud heights.

In the following, we discuss how far our assumptions and the characteristics of the used datasets could explain our findings, focussing particularly on those "zero" $\mathrm{NO}_{2}$ events.

\section{1 $\mathrm{NO}_{2}$ column densities}

In this study we focus on $\mathrm{NO}_{2}$ observations over active lightning systems, i.e. over cumulonimbus clouds. Such bright clouds may potentially affect the DOAS retrieval in two ways:

a. Bright clouds might lead to saturation of the detected radiances, with hardly predictible consequences for the spectral retrieval of $\mathrm{NO}_{2}$ SCDs. We thus checked the uncalibrated detector counts (binary units) per coadding over high clouds, and found values lower than 

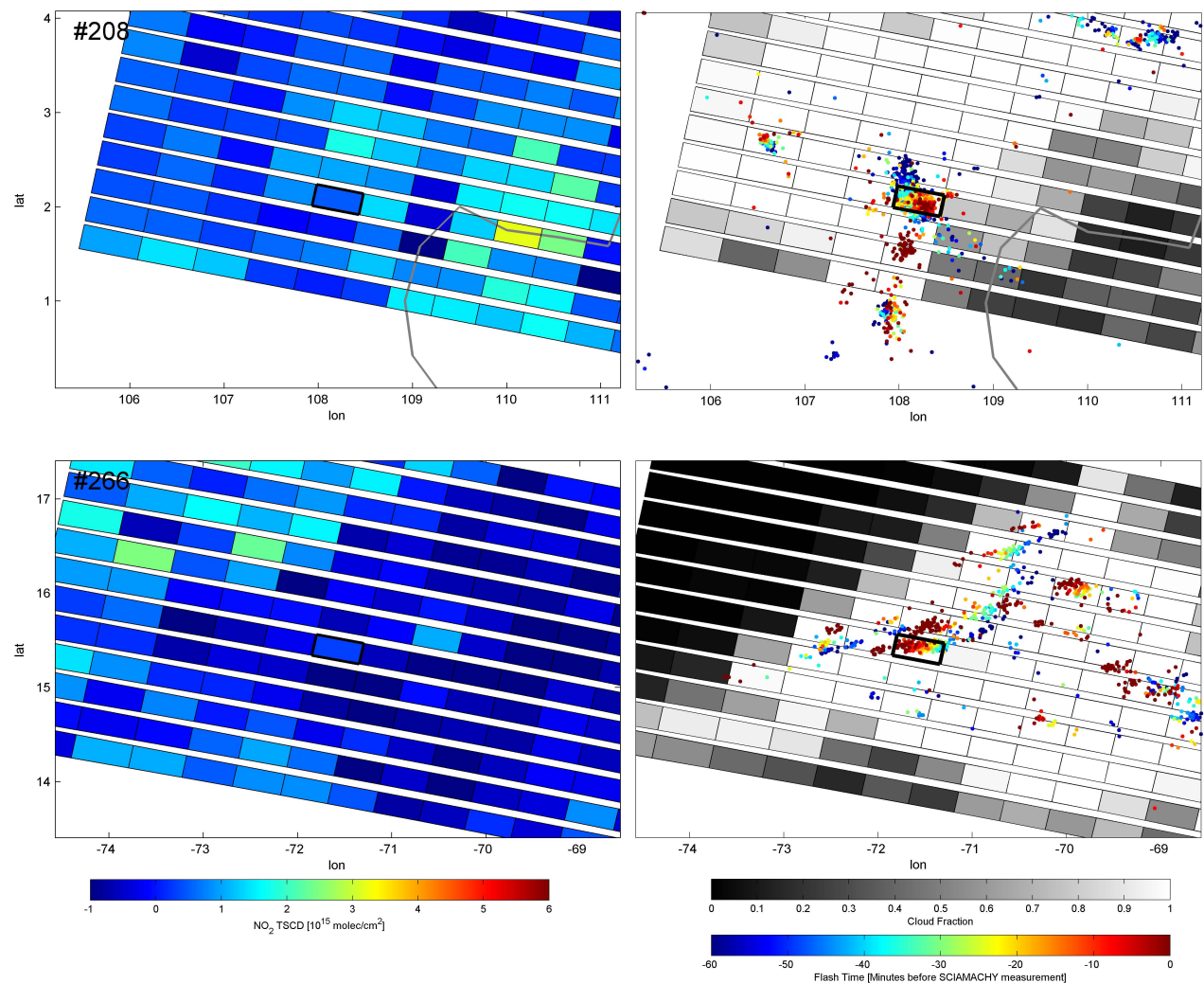

Fig. 5. Events \#208 on 20 August 2007 (top) and \#266 on 15 July 2008 (bottom). Left: $\mathrm{NO}_{2}$ TSCD. Right: FRESCO Cloud fraction (greyscale) and time of individual WWLLN flashes relative to the SCIAMACHY measurement (color).

maximum counts measured at higher latitudes (with longer integration times). In addition, the fit residuals show no increased values over high clouds.

b. Clouds affect the observed spectral structures in different ways, for instance by polarization effects (as SCIAMACHY is polarization dependent). Also inelastic scattering due to rotational and vibrational Raman is affected by clouds. Another effect of clouds is the shielding of (spectral dependent) absorbers below, including spectral reflectance at the ground. In particular over oligotrophic oceans with low chlorophyll concentrations, absorption and vibrational Raman scattering in liquid water affects the $\mathrm{NO}_{2}$ retrieval (see also Beirle et al., 2010). Changes of the DOAS-fit settings indeed reveal slight cloud interferences: The contrast of $\mathrm{NO}_{2}$ SCDs for clouded versus cloud-free ground pixels over the remote Pacific depends on fit settings like polynomial degree and spectral window. However, these effects are only in the range of some $10^{14} \mathrm{molec} / \mathrm{cm}^{2}$.

The derived TSCDs are - by definition of the stratospheric correction - excess TSCDs with respect to the Pacific. Consequently, a. negative (unphysical) TSCD occasionally occur in case of a local overestimation of the stratospheric column, and

b. we generally underestimate real clear-sky $\mathrm{NO}_{2}$ TSCDs by about $0.5 \times 10^{15} \mathrm{molec} / \mathrm{cm}^{2}$ (Martin et al., 2002). However, we can not simply add such an offset to the $\mathrm{NO}_{2}$ TSCDs used in this study, since the $\mathrm{NO}_{2}$ TSCDs of interest are observed under cloudy conditions, affecting the $\mathrm{NO}_{2}$ AMFs. It is difficult to quantify this effect, as, in addition, convection also modifies the profile of the background $\mathrm{NO}_{2}$; the uplift of $\mathrm{NO}_{2}$ generally leads to increased AMFs, i.e. higher TSCDs. But this is partly compensated by a concurrent decrease of the $\mathrm{NO}_{2} / \mathrm{NO}_{\mathrm{x}}$ ratio (see also Beirle et al., 2009). However, the Pacific tropospheric background is quite small (compared to the expected response in $\mathrm{NO}_{2}$ TSCD due to $\mathrm{LNO}_{\mathrm{x}}$ ) and thus does not affect our general findings.

\subsection{Sensitivity of satellite observations for freshly produced $\mathrm{LNO}_{\mathbf{x}}$}

For the translation of $\mathrm{NO}_{2}$ TSCDs to $\mathrm{NO}_{\mathrm{x}}$ TVCDs, we apply the sensitivity $E$ of 0.46 , as derived by Beirle et al. (2009) from a one-week episode of a thunderstorm simulation by a cloud resolving chemistry model. The model run covers all 
stages of thunderstorm evolution and thus allows to estimate $E$ for a large variety of atmospheric conditions, while the simulated sensitivities for individual model columns show a surprisingly low variability. In particular, $E$ is almost independent on cloud optical thickness, i.e. the sensitivities for core, anvil, and outflow regimes are quite similar. Above all, almost no pixels with zero sensitivity have been found, i.e. the model does not reproduce situations in which the $\mathrm{LNO}_{\mathrm{x}}$ is completely hidden from the satellite's view. The derived sensitivities are also robust with respect to vertical shifts of the $\mathrm{NO}_{\mathrm{x}}$ profile (see Beirle et al., 2009).

Model results generally are subject to uncertainties, and the simulated (maritime) thunderstorm might not be representative for all thunderstorms investigated in this current study. However, the general pattern of the profiles of $\mathrm{NO}_{2}$ box-AMFs (high at the cloud top and decreasing towards the cloud bottom) and of the $\mathrm{NO}_{2} / \mathrm{NO}_{\mathrm{x}}$ ratio (low at the cloud top and increasing towards the cloud bottom) are basic properties of (cumulonimbus) clouds, which automatically results in a maximum sensitivity at the cloud middle. As soon as $\mathrm{LNO}_{\mathrm{x}}$ is present there, it becomes visible from space. Thus, the only plausible explanation for a scenario of completely "hidden" $\mathrm{LNO}_{\mathrm{x}}$ would be a situation with all $\mathrm{LNO}_{\mathrm{x}}$ placed below the cloud. Such $\mathrm{LNO}_{\mathrm{x}}$ profiles might result from CG flashes occuring downwind (instead of inside) the updraft cores (compare Dye et al., 2000). However, such exclusively below-cloud $\mathrm{LNO}_{\mathrm{x}}$ profiles are contrary to the commonly accepted "C-shape". In contrast, for $\mathrm{LNO}_{\mathrm{x}}$ profiles with a large fraction of $\mathrm{NO}_{\mathrm{x}}$ in the middle troposphere, as have been recently simulated by Ott et al. (2010), the sensitivity of satellite measurements for $\mathrm{LNO}_{\mathrm{x}}$ would be even higher than 0.46 .

\subsection{WWLLN}

The annual DE of WWLLN was estimated by a quite simple comparison of annual FRD to the LIS/OTD climatology (see Appendeix A1). As the addition of stations to WWLLN can happen on any day within the year, the estimated annual mean DE maps are systematically too high for some regions up to the date when a new station is added, and too low afterwards. In addition, lightning statistics may not be sufficient after just one year, especially over oceanic regions, where also statistics of the LIS/OTD climatology are poor. Both effects are definitely causing rather high error bars in the estimated DE, and thus would dampen the expected correlation of FRD to $\mathrm{NO}_{2}$ TSCDs. However, these errors are to a large part of statistical nature, and thus can not explain the discrepancy of the absolute level of $\mathrm{NO}_{2}$ TSCDs to our expectation. In addition, a particular focus on events for high DE of about $10 \%$ and more (in 2007 and 2008), where estimated FRD are more reliable, results in basically the same findings.

We also investigated the diurnal cycle of the WWLLN DE by comparison with the LIS/OTD diurnal cycle (see Appendix A2). We found no indication that DE is signifi- cantly different for the SCIAMACHY observation time of 10:00 a.m. local time.

To further check the estimated DE of WWLLN $D_{\text {clim, }}$ we also directly compared the number of individual flash counts from WWLLN to LIS flash counts whenever a coincident TRMM overpass occured (Appendix A3). We therefore define "coincidence" as a LIS measurement containing the SCIAMACHY pixel center within a time window of $2 \mathrm{~h}$ before up to $1 \mathrm{~h}$ after the SCIAMACHY time. As LIS is an orbiting satellite, the observation duration at a specific location is rather short (about $1 \mathrm{~min}$ ). Nevertheless, we found 42 out of 287 events, where coincident LIS measurements are available. For these coincidences, we compared LIS flash counts to WWLLN flash counts in the same time interval within the LIS field of view, thereby estimating also an instantaneous DE $D_{\text {inst }}$. The resulting values $D_{\text {inst }}$ are presented and discussed in Appendix A3.

The comparison of $D_{\text {clim }}$ and $D_{\text {inst }}$ (Fig. A6c in Appendix A3) reveals a large scatter, which is expected due to the short time period of coincident observations. In addition, $D_{\text {inst }}$, derived from coincident LIS measurements, is systematically higher (by a factor of about 3 ) than $D_{\text {clim }}$ derived from the LIS/OTD climatology. This is an interesting finding, which can not be explained by the diurnal cycle of the WWLLN DE (see Appendix A2). Instead, it indicates a systematically higher DE for the selected events of high flash rate densities. This higher DE is likely related to above-average peak currents: Abarca et al. (2010) report on a distinct morningtime maximum of WWLLN flashes with high peak currents (see Fig. 5d therein). The WWLLN DE for such high peakcurrent flashes would be above average (the relation of DE and peak currents is almost linear up to $50 \mathrm{kA}$, Rodger et al., 2009), and our demand for high FRD probably selects events with high peak-current flashes.

If we use $D_{\text {inst }}$ instead of $D_{\text {clim }}$ for the calculation of PE, the results are on average higher by a factor of 2.8 (for the 42 coincidences). One could thus argue that we generally have to scale our resulting PE by a factor of 3 accordingly. But as long as the increased instantaneous DE is due to aboveaverage peak currents, we would also expect that the respective flashes have $\mathrm{LNO}_{\mathrm{x}}$ production $P$ above average, since high current flashes also produce more $\mathrm{LNO}_{\mathrm{x}}$. This is also an almost linear effect, as shown in Wang et al. (1998). Thus, the observed discrepancy between FRD and $\mathrm{NO}_{2}$ TSCD remains more or less the same, as both effects (the increase in $\mathrm{DE}$, thus the decrease in FRD, and the increase in PE due to high-current flashes) cancel each other out largely.

\subsection{Definition of events of "high" lightning activity}

One has to keep in mind that SCIAMACHY measurements are performed at about 10:00 a.m. LT. Thus, the selection of events of high lightning activity coinciding with SCIAMACHY is rather special, and the respective flashes may not be representative. In particular, most events have been found 
over ocean, where lightning activity is quite independent from daytime, while continental flashes show a strong afternoon peak (in addition, some continental events are skipped due to probable interference of anthropogenic $\mathrm{NO}_{\mathrm{x}}$ ).

Our indications for rather low $\mathrm{LNO}_{\mathrm{x}}$ production may thus be specific for maritime morning-time flashes. However, we performed a similar case study using OMI observations (02:00 p.m.) which generally yields the same results (though the spatial correlation of TSCDs to FRD is more complex due to the smaller OMI ground pixel sizes).

\subsection{Relation of $\mathrm{NO}_{2}$ TSCDs and WWLLN FRD}

For our estimation of the $\mathrm{LNO}_{\mathrm{x}}$ production per flash, we assume that the produced $\mathrm{LNO}_{\mathrm{x}}$ stays within the SCIAMACHY pixel for the considered time window of one hour. We thus neglect (a) chemical loss, which is well justified as the lifetime of $\mathrm{NO}_{2}$ is of the order of days in the upper troposphere, and (b) dilution and outflow.

We argue that this neglection is admissible, as the dimension of SCIAMACHY ground pixels is about $30 \times 60 \mathrm{~km}^{2}$. The movement of the flash cluster, which can be tracked by the color-coded flash time in Figs. 3-5, indicates wind speeds of the same order of magnitude, i.e. $30-60 \mathrm{~km} / \mathrm{h}$.

We are aware that still some fraction of the $\mathrm{LNO}_{\mathrm{x}}$ is "lost" by outflow from the SCIAMACHY ground pixel. However, this is at least partly compensated by some inflow of $\mathrm{LNO}_{\mathrm{x}}$ from neighbouring pixels, which is neglected as well in our study. In addition, also the FRD is generally underestimated due to the restriction to $1 \mathrm{~h}$.

The event maps generally do not indicate a considerable enhancement of the neighbouring TSCDs in wind direction (as indicated by the movement of WWLLN flashes). Thus, we see no evidence that outflow to neighbouring pixels would let us seriously overlook the produced $\mathrm{LNO}_{\mathrm{x}}$ by focussing on the single event groundpixel. In particular, outflow can not explain the findings of virtual no $\mathrm{NO}_{2}$, like e.g. for event \#266.

From a sensitivity study, involving also the $\mathrm{NO}_{2}$ TSCDs of the 8 direct neighbouring ground pixels, we conservatively estimate the loss of $\mathrm{LNO}_{\mathrm{x}}$ due to transport being less than $50 \%$, i.e. the PEs might be underestimated up to $100 \%$. But even if the estimated PEs would be doubled, the discrepancy to literature values remains.

\subsection{High variability of PE}

We observe a very high variability of $\mathrm{NO}_{2}$ TSCDs and PE for the detected lightning events. This is, to some extent, in accordance to a very wide range of reported $\mathrm{NO}_{\mathrm{x}}$ levels in and around thunderstorms and estimates of PE in literature (Schumann and Huntrieser, 2007). This wide range might be partly related to difficulties in aircraft observations, different lightning detection systems, and fundamental shortcomings in measurement techniques, and thus may just reflect the high observational uncertainties. But we might have to accept that lightning itself is a highly variable phenomenon, and PE is a highly variable quantity, varying strongly from thunderstorm to thunderstorm, and even from flash to flash. Consequently, one has to be aware that published estimates of $\mathrm{PE}$ are potentially biased towards too high values, since any finding of significantly enhanced $\mathrm{NO}_{\mathrm{x}}$ in the vicinity of lightning is likely to be published, while measurements of no or low levels of $\mathrm{NO}_{\mathrm{x}}$ might be discarded. This phenomenon is known as "publication bias" (e.g., Scargle et al., 2000).

Our category B results are in accordance to a $\mathrm{LNO}_{\mathrm{x}}$ production of the order of $2-3 \times 10^{25} \mathrm{molec} /$ flash, which is at the lower end of current estimates (Schumann and Huntrieser, 2007). However, the low PE values for category $\mathrm{C}$ results are far below any value reported in literature.

\subsection{Factors determining PE}

Several quantities have been discussed in literature to be determinative for the PE, i.e. the $\mathrm{LNO}_{\mathrm{x}}$ produced per flash.

As a consequence of the Zel'dovich mechanism, PE increases with energy and peak current (Wang et al., 1998). Flashes of low peak current are thus less productive concerning $\mathrm{LNO}_{\mathrm{x}}$. This might in principle be a possible explanation for lightning without $\mathrm{NO}_{2}$ production (category $\mathrm{C}$ ). However, as we use FRDs based on WWLLN flash counts, we implicity (at least partly) account for this: a thunderstorm with flashes of low peak current would probably produce only a small amount of $\mathrm{NO}_{\mathrm{x}}$, but due to dependency of WWLLN DE on peak current, only few flashes would be detected. The threshold of $F>1 / \mathrm{km}^{2} /$ h thus selects, at the same time, events with many flashes as well as events with not too low peak currents. Since both, WWLLN DE and PE, increase almost linearly with peak current, we probably can not explain the category $\mathrm{C}$ events by less productive flashes due to low peak currents.

Huntrieser et al. (2008) report on relatively low PE for tropical thunderstorms during the TROCCINOX campaign in Brazil, in contrast to subtropical thunderstorms, and could relate this to a difference in average stroke lengths. They propose that tropical thunderstorms have generally shorter flash lengths, and are thus generally less productive with respect to $\mathrm{LNO}_{\mathrm{x}} /$ flash, than subtropical thunderstorms, as a consequence of enhanced vertical wind shear of the latter. In Huntrieser et al. (2009) correlations of $P$ with vertical wind shear are reported using in-situ measurements from the TROCCINOX and SCOUT-O ${ }_{3}$ campaigns.

Indeed, Fig. 1 reveals a latitudinal dependency of $P_{\text {event }}$, showing higher values in the subtropics. However, this is mainly a consequence of the high values for $P_{\text {event }}$ close to the US Eastcoast and in the Mediterranean, as represented by the category A examples \#115 and \#191. As discussed before, for these events, high $\mathrm{NO}_{2}$ TSCDs are observed also for pixels without recent lightning activity, indicating the impact of aged $\mathrm{LNO}_{\mathrm{x}}$ and/or outflow of anthropogenic pollution, so 
that the observed latitudinal dependency of $P_{\text {event }}$ should not be overinterpreted. But at least most events with low $P$ are indeed tropical events, which might thus be less productive due to low wind shears.

Huntrieser et al. (2009) also proposed that warm rain processes, which might be dominant for the tropical morningtime thunderstorms of this study, may result in very short flash components. I.e., though the detected events show - by selection - high FRD, these flashes might generally be less productive in producing $\mathrm{NO}_{\mathrm{x}}$ compared to flashes for mixedphase precipitation processes with probably longer flash channels. To check whether the detected events show mixedphases, we investigated Polarization-Corrected Temperatures (PCTs) from the 37 and $85 \mathrm{GHz}$ Radar TMI onboard TRMM, whenever coinciding (see Appendix B). For several events, quite low PCTs are observed $(<210 \mathrm{~K}$ down to $<180 \mathrm{~K}$ at $37 \mathrm{GHz}$, and $<110 \mathrm{~K}$ down to $<70 \mathrm{~K}$ at $85 \mathrm{GHz}$ ), which classify the respective events as intense thunderstorms (Zipser et al., 2006) and indicate the presence of hail (Cecil, 2009). The PCT at $37 \mathrm{GHz}$ is slightly anticorrelated to $P_{\text {event }}(R=$ -0.51 , see Fig. B1 in Appendix B), i.e. PE tends to be higher for low PCT, which might indeed indicate a link of mixedphase precipitation and lightning PE, but statistics of this comparison are rather poor, and there are still some events with lof PCT $(<201 \mathrm{~K})$ and yet low PE.

Obviously, lightning is a very complex phenomenon, resulting in high variability of $\mathrm{PE}$, and systematic dependencies on several parameters which are still poorly understood. Aiming for one single value of $P$ (or, as a first specification, two universal values $P_{\mathrm{IC}}$ and $P_{\mathrm{CG}}$ ) is probably not appropriate for the representation of global $\mathrm{LNO}_{\mathrm{x}}$ production. The simple relation of $P$ to flash properties like energy, peak current, or flash length is a first step, but increases the observational needs.

Further diversification of flash characteristics is probably needed. Rahman et al. (2007) measured the $\mathrm{LNO}_{\mathrm{x}}$ production from rocket-triggered lightning and conclude that steady currents, and not return strokes, are the primary $\mathrm{LNO}_{\mathrm{x}}$ producers. Cooray et al. (2009) analyzed the produced number of $\mathrm{NO}_{\mathrm{x}}$ molecules for various flash processes in the laboratory, and confirm that return strokes produce relatively few $\mathrm{NO}_{\mathrm{x}}$, while other processes such as leaders or continuing currents are rather important.

Thus, one hypothesis which could explain the absence of $\mathrm{LNO}_{\mathrm{x}}$ for events of high lightning activity might be the occurence of flashes with strong return strokes, making the flashes "visible" for LIS and WWLLN, but low steady currents (producing small amounts of $\mathrm{LNO}_{\mathrm{x}}$ ). However, this is quite speculative and hard to substantiate with the currently available lightning datasets on global scale.

\section{Conclusions}

We performed a systematic investigation of SCIAMACHY measurements of $\mathrm{NO}_{2}$ for coincident lightning events with high flash rate densities as observed by WWLLN, resulting in 287 "events". For each event, an individual estimate for the Production Efficiency (PE, i.e. $\mathrm{LNO}_{\mathrm{x}}$ production per flash) is derived.

In contrast to our a-priori expectation of clearly enhanced $\mathrm{NO}_{2}$ column densities due to the considered high flash rate densities, the resulting values for PE are highly variable, and far below literature values. Surprisingly, $\mathrm{NO}_{2}$ column densities do not correlate with flash rate densities.

For some events, strongly enhanced $\mathrm{NO}_{2}$ column densities are observed. But the spatial pattern of $\mathrm{NO}_{2}$ cannot be explained by the fresh flashes alone; instead, aged $\mathrm{LNO}_{\mathrm{x}}$ and/or continental outflow of anthropogenic pollution contributes significantly.

Few events show a good spatial correlation of flashes and enhanced $\mathrm{NO}_{2}$ column densities. For these events, $\mathrm{PE}$ was rather low $\left(2-3 \times 10^{25} \mathrm{molec} / \mathrm{cm}^{2}\right)$, which would correspond - by simple extrapolation - to a global annual $\mathrm{LNO}_{\mathrm{x}}$ production of the order of $1 \mathrm{Tg} \mathrm{N}$.

The majority of the events has very low PE $\left(<1 \times 10^{25} \mathrm{molec} /\right.$ flash $)$. We do not see any reason to abandon these events as artefacts or outliers. However, we could not find any characteristics of these less productive events making them different from the others (except that they are mostly, but not exclusively, at low latitudes), and find no plausible explanation for these events. Further investigations have to reveal how far these low estimates of $\mathrm{PE}$ are related to the implicit and explicit selections of events due to the WWLLN detection efficiency, SCIAMACHY observation time, the pollution mask, and the focus on high flash rate densities, resulting in acitve morning-time thunderstorms, mostly over oceans. From the continental events of this study, however, we come to essentially the same conclusions.

Overall, our results are not consistent with the current estimates of $P$ of about $15(2-40) \times 10^{25} \mathrm{molec} /$ flash. While this might be related to the specifics of morning time flashes and our focus on high FRD, it could also indicate that PE is overestimated in literature. We see two possible reasons for this:

1. PE estimates in literature might be generally biased high ("publication bias", Scargle et al., 2000): Observations of high PE ("positive" results) have likely been published, while observations of low PE ("negative" results) might have been discarded as non-significant or non-conclusive. But for the estimation of a sound, unbiased mean, information on both tails of the statistical distribution of the $\mathrm{NO}_{\mathrm{x}}$ production per flash is needed. We encourage feedback to this hypothesis from scientists having performed in-situ measurements. 
2. A large fraction of estimates of $\mathrm{NO}_{\mathrm{x}}$ production by lightning is based on experiments performed in the US, for several reasons: there is a large scientific community, a good infrastructure (lightning networks, aircraft campaigns), and lightning activity is generally high as well. From our study, we find highest PE around the US. This might be related to higher flash lengths of subtropical thunderstorms, but could also simply be a consequence of uplifted anthropogenic pollution. In either case, extrapolations of PE estimates over the US to global scale are possibly too high.

Obviously, the matter of $\mathrm{NO}_{\mathrm{x}}$ production by lightning still leaves many questions open, and lightning characteristics are probably too complex to be reasonable represented by just one universal number for PE. Within the ongoing studies on $\mathrm{LNO}_{\mathrm{x}}$ production, the analysis of satellite measurements of $\mathrm{NO}_{2}$ allows an independent approach, complementing laboratory and in-situ measurements.

\section{Appendix A}

\section{The detection efficiency of WWLLN}

\section{A1 DE from LIS/OTD climatology}

For a quantitative relation of $\mathrm{NO}_{2}$ TSCDs to FRD, the number of flashes actually measured by WWLLN has to be scaled according to the respective detection efficiency (DE). Thus, estimates of WWLLN DE are required as function of time and place. For this purpose, we calculate mean annual FRD from individual WWLLN flash counts on a map of $1^{\circ}$ resolution for each year 2004-2008 (Fig. A2), and set them in relation to the FRD from LIS/OTD climatology (Fig. A1) (see LIS/OTD documentation, 2007) to define the climatological DE $D_{\text {clim }}$ (Fig. A3) according to Eq. (2).

To avoid biased DE caused by strong localiced thunderstorms (which may potentially lead to high local FRD above average and thus to a too low DE estimate), both, LIS/OTD and WWLLN FRD are spatially smoothed by a Gaussian function with $\sigma=1.5^{\circ}$. Note that flash rate densities are generally low over oceans, and the climatological FRDs are derived from the extrapolation of rather few actual flash counts (typically 10-30 for a FRD of 1 flashes $/ \mathrm{km}^{2} /$ year). We thus skip regions with $F_{\text {LIS/OTD }}<1$ flashes $/ \mathrm{km}^{2} /$ year, to avoid division by small numbers with respective high uncertainties. For the remaining oceanic regions, statistical fluctuations are still significant, but partly eliminated by the applied spatial smoothing.

Figure A3 shows the resulting DE for 2005 and 2008 exemplarily. DE is highest over Australia and Indonesia, as WWLLN evolved from a regional network initiated in New Zealand (Dowden et al., 2008). Over the years, the number of participitating stations increased from 19 (2004) to 30 (2007) (Rodger et al., 2009), which improves the DE also for other parts of the world, in particular for central and northern America.

The DE of 2005 can be compared to the estimate given in Rodger et al., 2006 (Figs. 13 and 14 therein), for April 2005, showing generally similar spatial patterns. However, a quantitative comparison also shows large deviations. Differences are expected for mainly two reasons: First, Rodger et al. (2006) estimate DE for one day (16 April 2005), while Fig. A3 shows our mean annual DE. Second, Rodger et al. (2006) explicitely estimate the DE for CG flashes (though WWLLN also detects IC flashes with sufficient peak currents), while our climatological approach based on LIS/OTD results in an "effective" DE for total (IC+CG) flashes. Consequently, we expect our DE to be lower by a factor of about 4 (for a IC/CG ratio of 3). One striking difference is that our estimated DE shows a clear land-ocean contrast, which is not visible in the estimate by Rodger et al. (2006). This is probably related to a land-ocean contrast in the DE of WWLLN, which is expected, since VLF radio waves propagate with less attenuation over seawater than over land. However, Lay et al. (2007) found only a small effect, with DE over ocean being 13\% higher (relative) than over land. The observed land-sea contrast might also be related to LIS/OTD characteristics, or a change in the IC/CG ratio between continents and oceans.

Jacobson et al. (2005) investigate WWLLN DE for both IC and CG flashes over Florida in summer 2004 by comparisons to the Los Alamos Sferic Array, and estimate a mean DE of about $1 \%$ for the considered region around $29^{\circ} \mathrm{N}, 82^{\circ} \mathrm{W}$. This is in good agreement with our estimated DE for this location in $2004(0.9 \%)$.

A further study on WWLLN DE has been published recently by Abarca et al. (2010), using the US national lightning detection network (NLDN) as ground truth. In Table 2 therein, they number the WWLLN DE (for CG+IC flashes) over the US for 2007-2008 as $2.9 \%$, matching pretty well our value for this period and region (1.8\% in 2007 and 3.9\% in 2008).

\section{A2 Diurnal cycle of WWLLN DE}

The climatological WWLLN DE defined above accounts for total flash counts independent of time of day, while our consideration of coincident SCIAMACHY measurements selects events at about 10:00 a.m. local time. We thus also investigate the diurnal cycle of the WWLLN DE by comparing WWLLN flash counts, grouped in 1-h bins according to local time, to the climatological LIS/OTD diurnal cycle, which is available on a $2.5^{\circ}$ grid. We investigate the diurnal cycle of WWLLN DE separately for continents and oceans by (a) gridding the WWLLN flash counts to the same grid as the LIS/OTD climatology, (b) integrating the flash counts of the respective continental/oceanic grid pixels for both WWLLN and LIS/OTD, and (c) defining DE for each hourly bin as ratio of the respective WWLLN and LIS/OTD flash counts. 
Coastal grid pixels, containing both ocean and continent, are skipped.

The diurnal cycles of LIS/OTD and WWLLN flash counts show the known afternoon peak over continents, and a minimum at about 10:00 a.m. (Fig. A4a, b). The time-shift of the afternoon peak of WWLLN relative to LIS/OTD might be related to the fact that different regions show different local times of the peak (Lay et al., 2007), and the regions are contributing differently to the total number of flashes for LIS/OTD than for WWLLN due to the regionally varying DE. Over oceans, the diurnal variations are small and show no clear pattern.

Over continents, mean WWLLN DE (Fig. A4c) is $1.9 \%$ at night and $1.5 \%$ at day. The slightly higher nighttime DE is in accordance with Abreu et al. (2010) and is likely related to the effect of day/night ionospheric changes on VLF wave propagation. However, the DE over oceans $(8.2 \%$ for both day and night) does not show a clear day/night pattern, but instead only moderate fluctuations (of the order of $\pm 10 \%$ relative change), which may partly be caused by statistical fluctuations due to the low number of flash counts for both LIS/OTD and WWLLN over oceans (compare Fig. A4b).

\section{A3 DE from concurrent LIS overpasses}

In addition to the comparison of WWLLN FRD to the LIS/OTD climatology, we also compared the flashes detected by WWLLN and LIS for individual lightning events. Of course, this approach requires coincident LIS overpass. If we search for LIS overpasses containing the event location within a time window of $2 \mathrm{~h}$ before up to $1 \mathrm{~h}$ after the event, and demand at least 5 LIS flashes during overpass, we find 42 of such coincidences. LIS flash counts and WWLLN flash counts within the LIS overpass time are shown in Fig. A5 for two events. In addition, also TRMM PCTs are displayed (see Appendix B).

The selected events illustrate two opposing situations: For event \#64, LIS counts 68 flashes, while WWLLN detects 2 flashes, which corresponds to our expectation according to the respective climatological DE of $2.3 \%$. Event \#171, on the other hand, is an example for a case where WWLLN flash counts (19) are almost as high as LIS flash counts (23), despite a climatological DE of $8.4 \%$. LIS measurements have taken place $99 \mathrm{~min}$ before $/ 43 \mathrm{~min}$ after the SCIAMACHY measurement, respectively.

For a quantitative comparison, we sum up LIS flash counts as well as the respective WWLLN flash counts within the LIS field of view for each coincidence. Figure A6a displays the respective flash counts. In Fig. A6b, corrected flash counts are shown: WWLLN flash counts are scaled by $1 / D_{\text {clim }}$, while LIS flash counts are scaled by $1 / 0.7$, according to the DE of LIS of 70\% at 10:00 a.m. Figure A6c displays the "instantaneous" WWLLN DE $D_{\text {inst }}$, defined as ratio of (actual) WWLLN and (corrected) LIS flash counts:

$D_{\text {inst }}:=N_{\text {WWLLN }} / N_{\text {LIS }}^{\text {corr }}$,
The ratio of two flash counts for a region of about $640 \times 640 \mathrm{~km}^{2}$ (LIS field of view) and a time interval of the order of $1 \mathrm{~min}$ (LIS overpass time at the event) is of course rather uncertain, and statistical deviations to the climatological DE are not surprising. Nevertheless, Fig. A6b and c indicate that instantaneous DE are systematically higher (on average by a factor of about 3 ) than the climatological ones.

The observed systematically enhanced instantaneous DE can not be explained by the diurnal cycle of WWLLN DE. Instead, it is probably a consequence of our focus on events with high FRD: Abarca et al. (2010) report on a distinct morning-time peak of WWLLN flashes with high peak currents (see Fig. 5c therein). Such high peak currents would be well detectable by WWLLN, which is strongly dependent on peak currents (approx. linear for a wide range of peak currents see Rodger et al., 2009).

\section{Appendix B}

\section{Polarization corrected temperatures from TRMM}

There are indications that PE might be related to warm rain vs. mixed-phase precipitation processes (Huntrieser et al., 2009). Thus, in order to investigate the presence of hail for the detected lightning events, we also analyzed polarizationcorrected temperatures (PCT) from brightness temperature measurements of TMI on TRMM for the coincident overpasses as defined in Appendix A. PCT are calculated as defined in Spencer et al. (1989) (for $85 \mathrm{GHz}$, see Eq. 3 therein) and Cecil et al. (2002) (for $37 \mathrm{GHz}$, see Eq. 2 therein). Low PCT are indicators for intense thunderstorms and the presence of hail (Toracinta and Zipser, 2001; Zipser et al., 2006; Cecil, 2009). PCT at $37 \mathrm{GHz}$ is shown as background greyscale map in Fig. A5 (Appendix B). As expected, the flash locations generally coincide with low PCT. For each available event, we define a "minimum PCT" by the minimum PCT value within a range of $200 \mathrm{~km}$ from the respective event. Figure B1 shows the correlation of minimum PCT at $37 \mathrm{GHz}$ with (a) minimum PCT at $85 \mathrm{GHz}$, (b) LIS flash counts, and (c) $\mathrm{NO}_{2}$ TSCD. PCTs at $37 \mathrm{GHz}$ and $85 \mathrm{GHz}$ are strongly correlated. Minimum PCT at $37 / 85 \mathrm{GHz}$ reach values down to $<180 /<70 \mathrm{~K}$, respectively, which are extremely low values (compare Zipser et al., 2006) and are strongly indicating hail (Cecil, 2009). Generally, events with low PCT at $37 \mathrm{GHz}$ also show low PCT at $85 \mathrm{GHz}$, but for some events PCT at $85 \mathrm{GHz}$ is low (about $100 \mathrm{~K}$ ), but medium for $37 \mathrm{GHz}$ (about $220 \mathrm{~K}$ ). LIS flash counts tend to be higher for low PCT, but the scatter is quite high due to the short time interval of LIS overpass. Also the $\mathrm{NO}_{\mathrm{x}} \mathrm{PE}$ per flash shows a slight tendency to be higher for low PCT, which would correspond to the hypothesis of higher $\mathrm{LNO}_{\mathrm{x}} \mathrm{PE}$ for flashes from intense thunderstorms. However, the scatter is high $(R=-0.54)$, and there are still several cases with low PCT (about $200 \mathrm{~K}$ ) and low PE. 

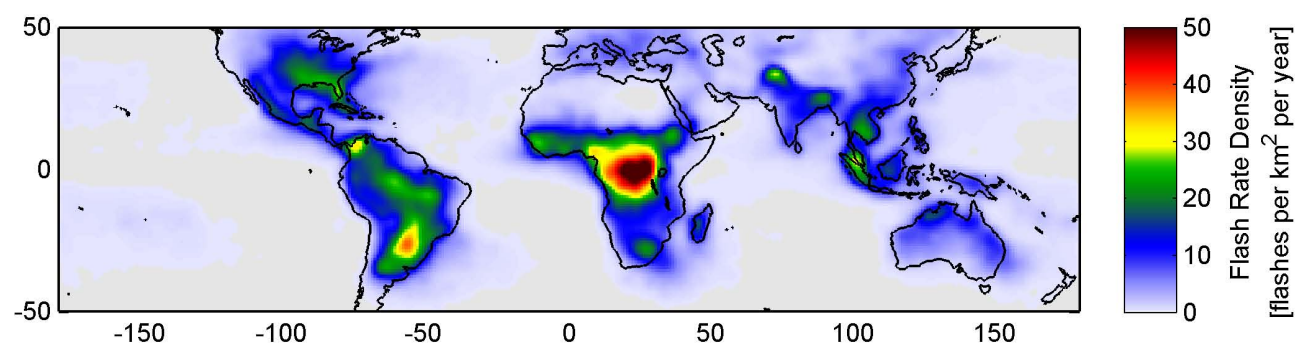

Fig. A1. Global map of the LIS/OTD climatological flash rate densities.
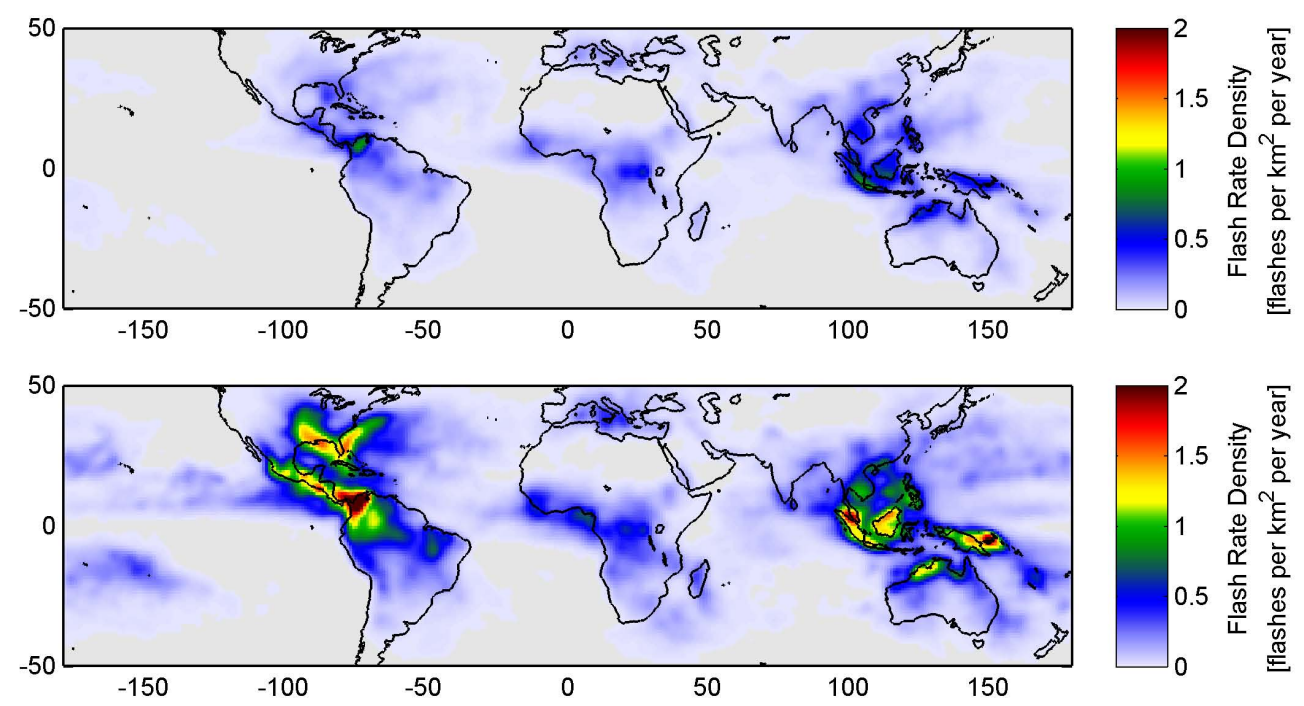

Fig. A2. Global map of the WWLLN flash rate density (uncorrected) in 2005 (top) and 2008 (bottom).
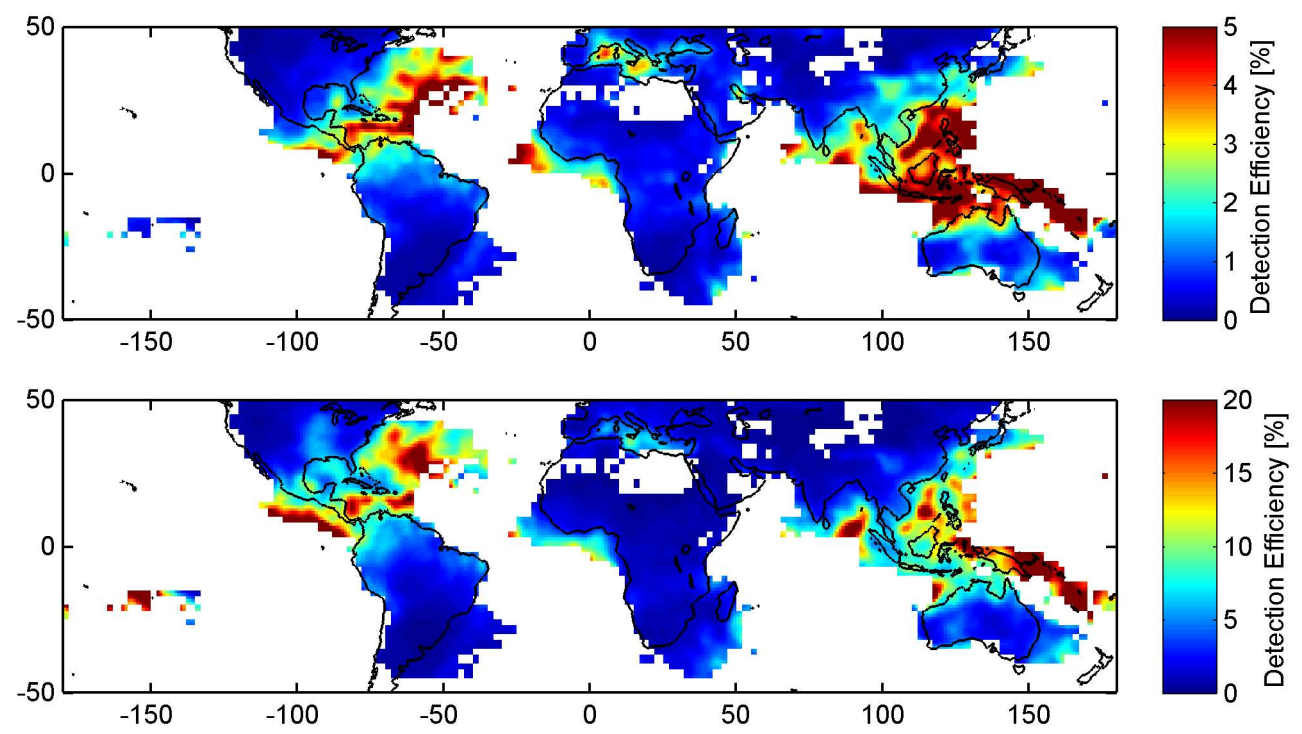

Fig. A3. Global map of the WWLLN detection efficiency $D_{\text {clim }}$ for 2005 (top) and 2008 (bottom). Note that the colorscales are different. 

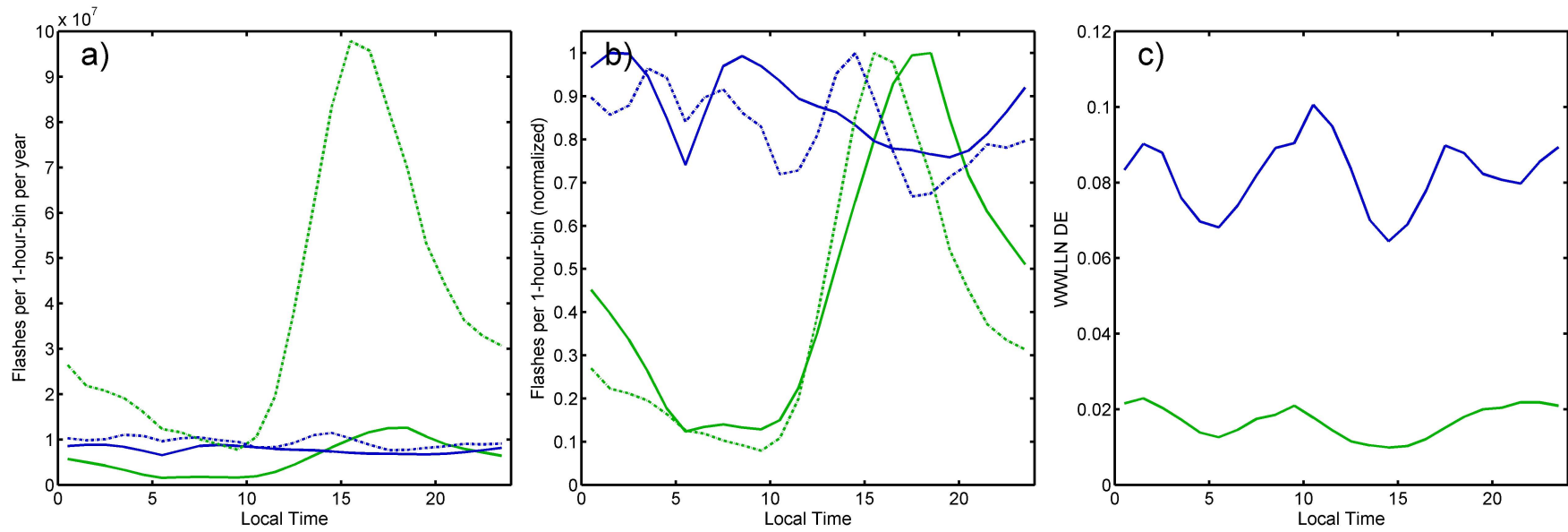

Fig. A4. Diurnal cycle of LIS/OTD (dotted) and WWLLN (straight) flash counts and WWLLN DE over oceans (blue) and continents (green). (a) Total number of flashes per 1-h bin and per year. WWLLN flash counts have been scaled up by a factor of 10 . (b) Normalized diurnal patterns of flash counts per 1-h bin. (c) Diurnal cycle of the WWLLN DE, defined as the ratio of the diurnal patterns of total flash counts as shown in (a).
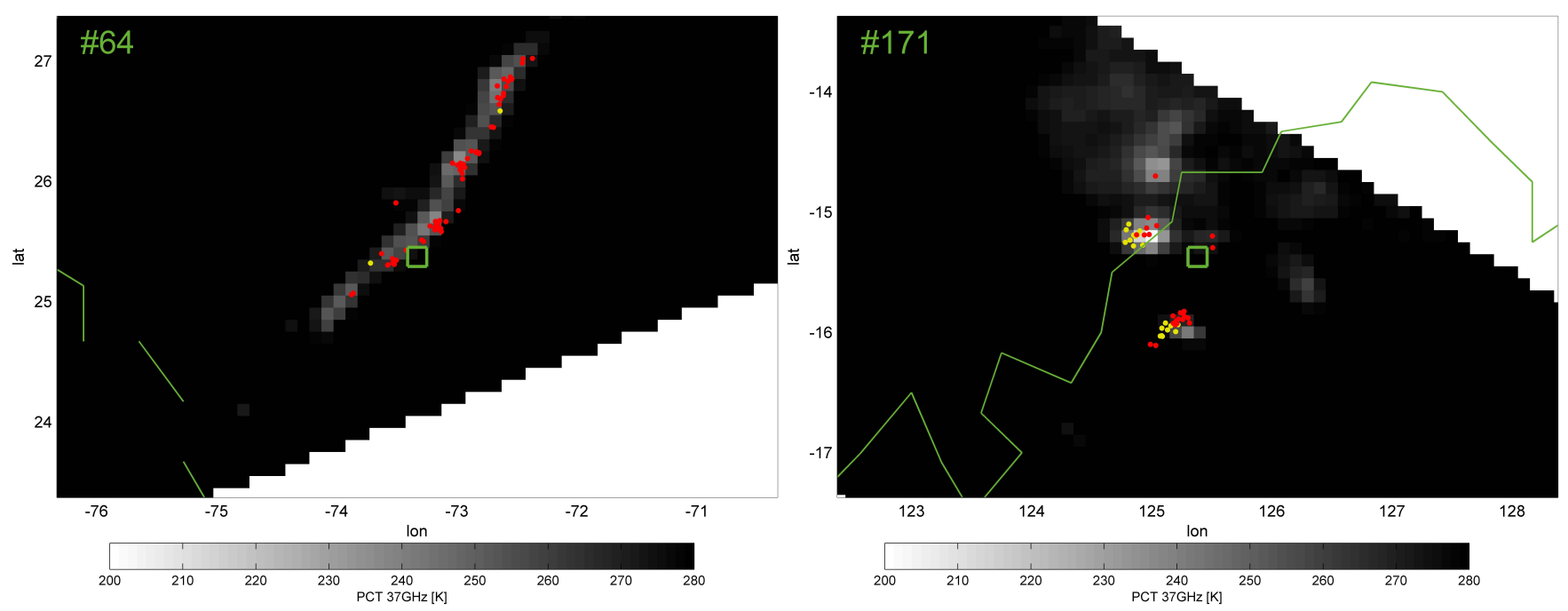

Fig. A5. TRMM overpasses close to the SCIAMACHY measurements for event \#64 (top) and \#171 (bottom). Red dots are flashes detected by LIS (68/23), while yellow dots are WWLLN flashes detected within the LIS overpass time (2/19). The green square marks the center coordinates of the respective SCIAMACHY pixels. The respective climatological DEs are $2.3 \%$ and $8.4 \%$, while the instantaneous DEs are $2.1 \%$ and $57.8 \%$, respectively. Greyscale background shows the PCT at $37 \mathrm{GHz}$ (minimum: $233 \mathrm{~K}$ (\#64)/202 K (\#171)) (see Appendix B). 

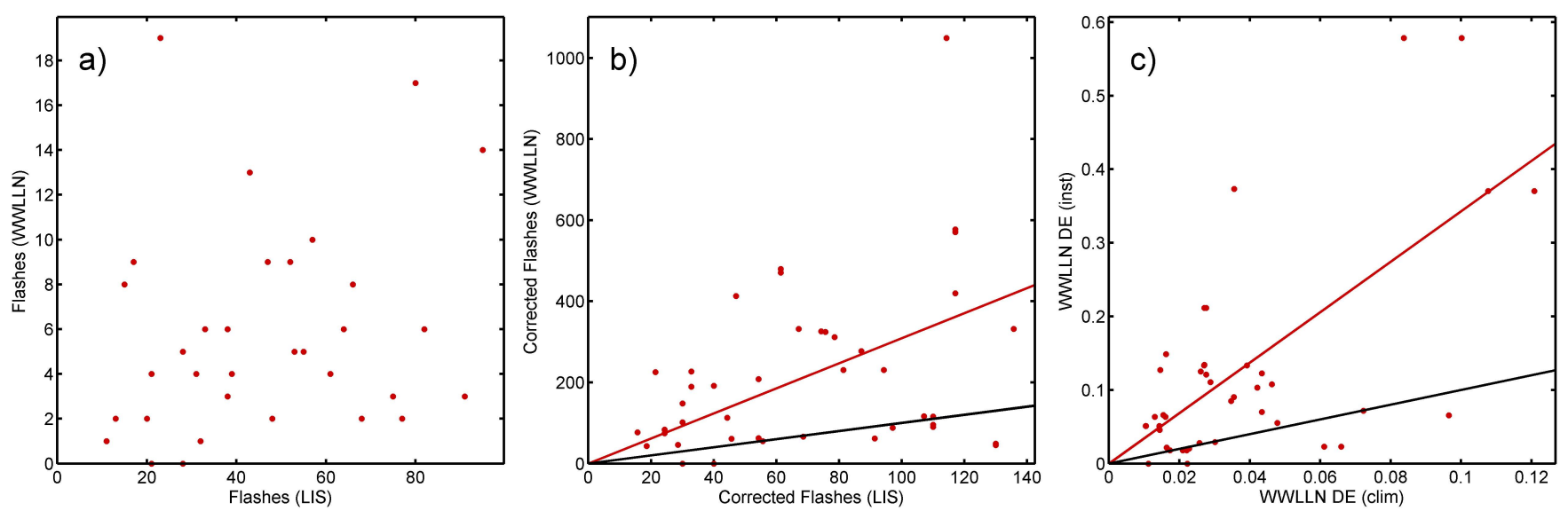

Fig. A6. Comparison of flash counts from LIS and WWLLN for LIS overpasses coinciding with SCIAMACHY for events of high lightning activity. (a) Scatterplot of the number of original flash counts from LIS and WWLLN. (b) Correlation $(R=0.35)$ of corrected flash counts from LIS (scaled by $1 / 0.7$ ) and WWLLN (scaled by $1 / D_{\text {clim }}$ ). The black line corresponds to $1: 1$. The slope of the fitted line through origin (red) is 3.1. (c) Correlation $(R=0.63)$ of $D_{\text {clim }}$ (Eq. 2) and $D_{\text {inst }}$ (Eq. A1). The black line corresponds to 1:1. The slope of the fitted line through origin (red) is 3.4 .
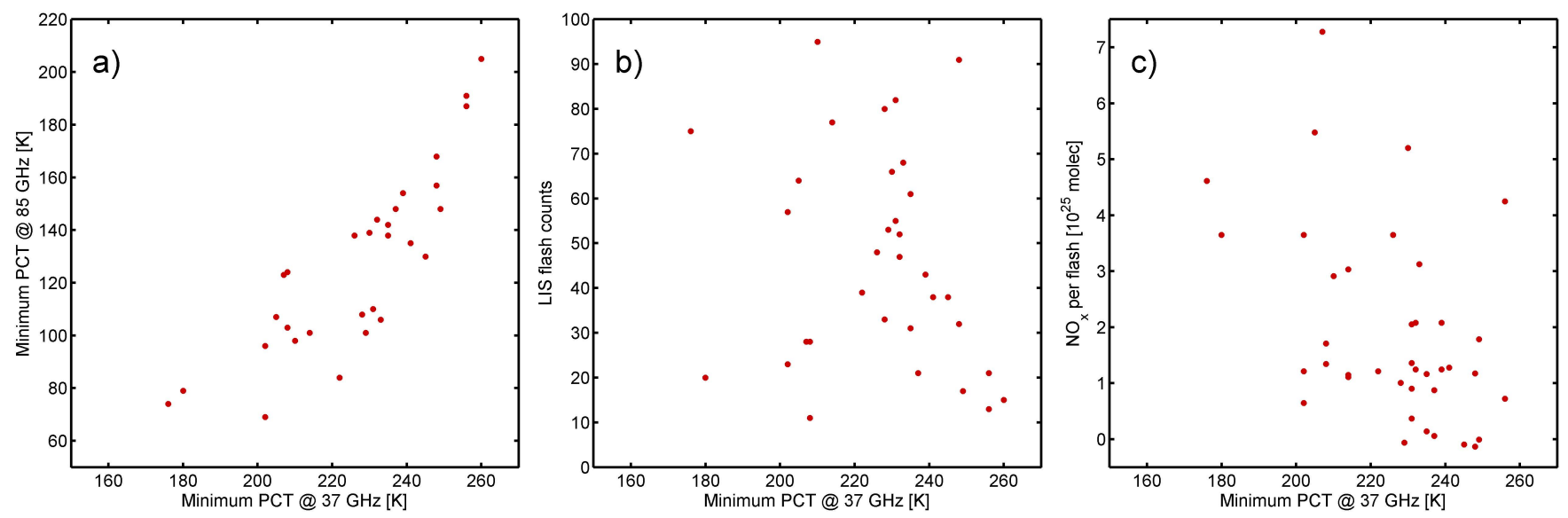

Fig. B1. Correlation of minimum PCT at $37 \mathrm{GHz}$ with (a) minimum PCT at $85 \mathrm{GHz}(R=0.84)$, (b) number of LIS flash counts $(R=-0.14)$, and (c) the production efficiency $P_{\text {event }}(R=-0.51)$, for the coincident TRMM overpasses.

\section{Appendix C}

\section{High $\mathrm{NO}_{2}$ events}

In the discussions of category A events (high $\mathrm{NO}_{2} \mathrm{TSCD}$ ), we argue that the pattern of enhanced $\mathrm{NO}_{2}$ for events \#115 and \#191 can not be explained by fresh $\mathrm{LNO}_{\mathrm{x}}$ production alone, but is probably due to aged $\mathrm{LNO}_{\mathrm{x}}$ and/or continental outflow of anthropogenic pollution. To support this hypothesis, we additionally analyzed (a) the flashes of the previous $40 \mathrm{~h}$, (b) HYSPLIT backtrajectories, and (c) MOPITT CO and SCIAMACHY absorbing aerosol index (AAI) observations. a. Figure $\mathrm{C} 1$ shows the occurence of WWLLN flashes back to $40 \mathrm{~h}$ prior to the SCIAMACHY measurement for events \#115 and \#191. Note that the clipping displays a larger region compared to Fig. 3. Again, dots indicate the time of WWLLN flashes relative to the SCIAMACHY measurement, but now up to $40 \mathrm{~h}$ back. The SCIAMACHY ground pixel of the respective event is shown as black rectangle.

High lightning activity several hours back in time can be observed for both events. 


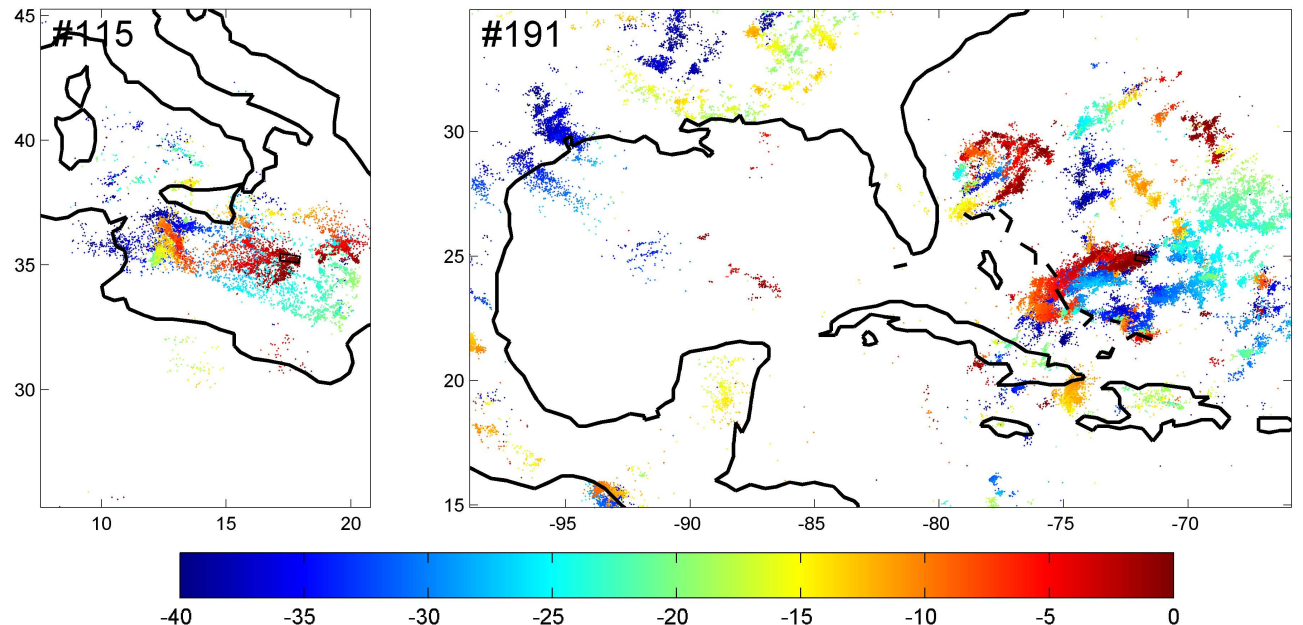

Fig. C1. Occurence of WWLLN flashes back to $40 \mathrm{~h}$ prior to the SCIAMACHY measurement for events \#115 (left) and \#191 (right). Note that the clipping shows a larger region compared to Fig. 3. Dots indicate the time of WWLLN flashes relative to the SCIAMACHY measurement up to $40 \mathrm{~h}$ back. The respective SCIAMACHY ground pixels of the events of high lightning activity are shown as black rectangles.
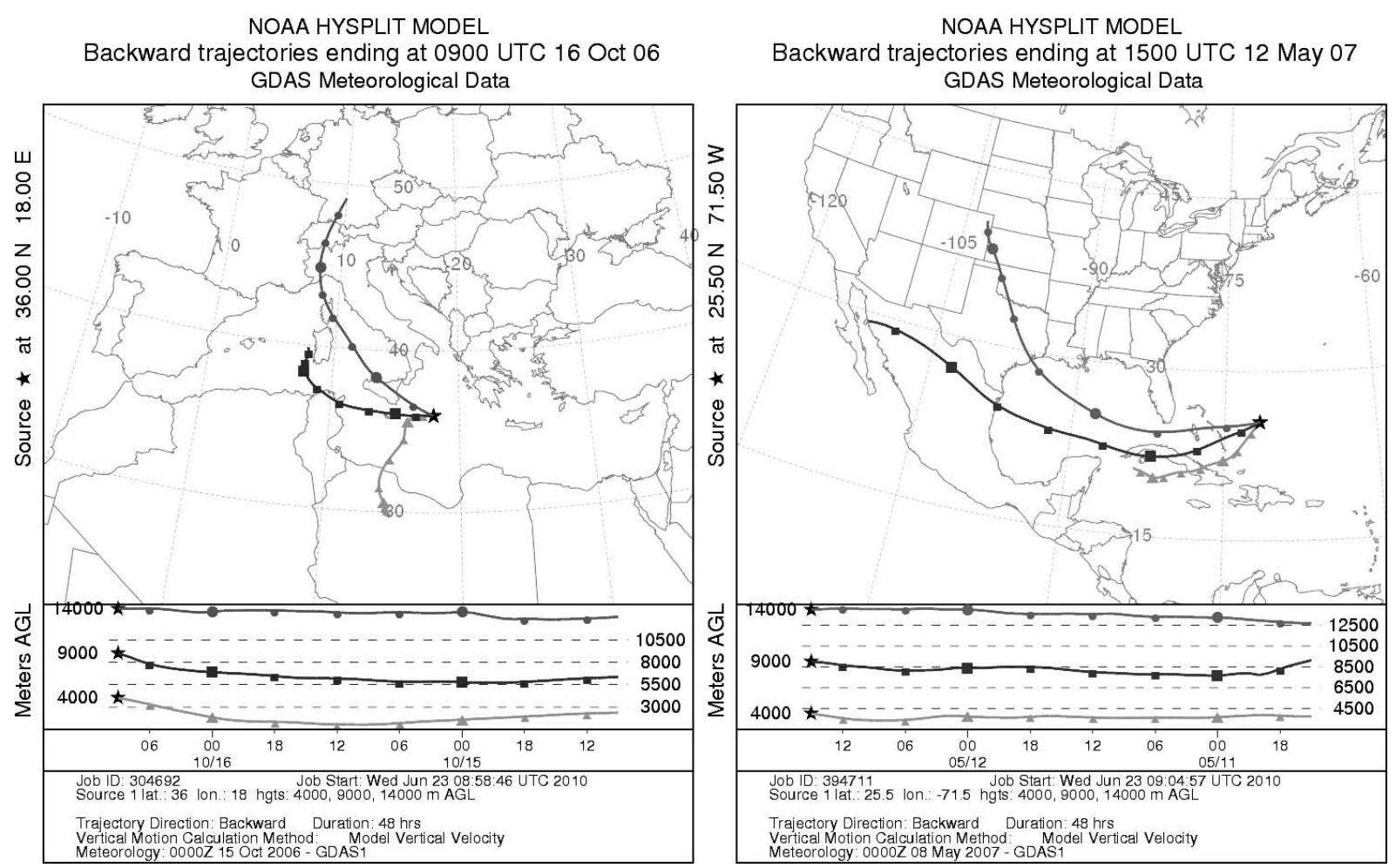

Fig. C2. HYSPLIT backtrajectories from the event location over $48 \mathrm{~h}$ for 3 different altitudes for events \#115 (left) and \#191 (right). Air-masses of continental (polluted) origin can only be identified for transport in the upper troposphere. 

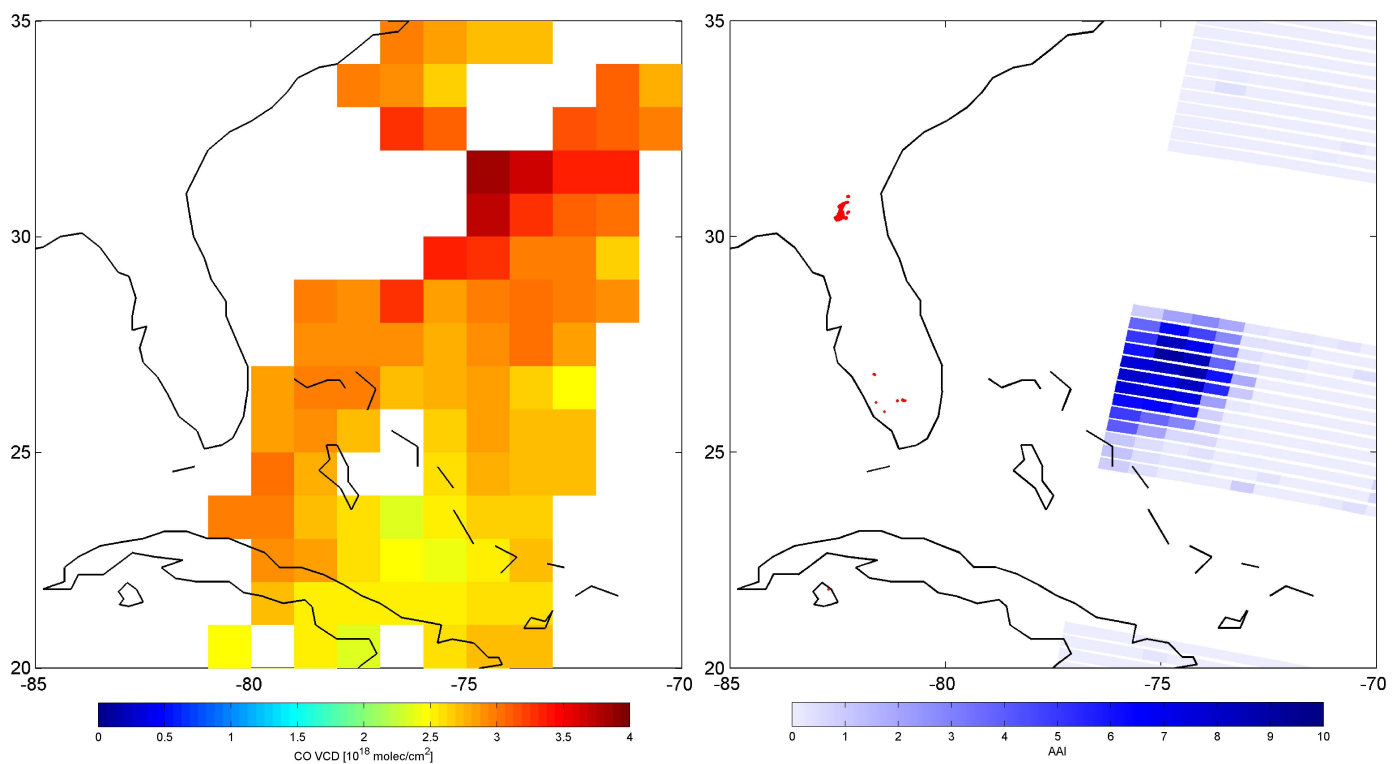

Fig. C3. Left: MOPITT CO VCD on 12 May 2007. Right: SCIAMACHY absorbing aerosol index (AAI) (Penning de Vries et al., 2009) on 12 May 2007. The red dots indicate fires detected by ATSR on 11 May 2007.

b. Figure $\mathrm{C} 2$ shows HYSPLIT backtrajectories, starting at the event, over $48 \mathrm{~h}$ for three different altitudes in the middle and upper troposphere.

For event \#115, the backtrajectory at $9 \mathrm{~km}$ altitude crosses the region south of Sicily where high lightning activity was observed over the last $40 \mathrm{~h}$. The backtrajectory at $14 \mathrm{~km}$ altitude indicates transport from continental Europe; the Po-valley in northern Italy is generally highly polluted with respect to $\mathrm{NO}_{2}$. However, from the WWLLN flash counts, we found no indication of deep convection over this region which would be necessary to uplift the boundary layer pollution to the upper troposphere.

For event \#191, again the backtrajectories match the track of WWLLN flashes over the last hours. In addition, the backtrajectory at $14 \mathrm{~km}$ altitude indicates transport from continental US; in this case, we actually find indication of deep convection about $40 \mathrm{~h}$ ago over Houston, Texas (Fig. C1b), which might have uplifted anthropogenic $\mathrm{NO}_{\mathrm{x}}$ to the upper troposphere, from where it might have been transported to the event location.

c. Figure C3 shows MOPITT CO VCD and the SCIAMACHY AAI. Both datasets show enhanced values in the vicinity of event \#191, but the spatial patterns do not match perfectly. The enhanced CO VCDs might again indicate anthropogenic outflow, but the high AAI clearly indicates biomass burning. In fact, ATSR detected fires in Florida on 11 May 2007, as also shown in Fig. C3.
Thus, though the different datasets do not reveal a clear and simple explanation for the expanded plume of enhanced $\mathrm{NO}_{2}$ TSCD on 12 May 2007, there are strong indications that other sources than lightning have contributed significantly.

Acknowledgements. Steffen Beirle was funded by the DFG (Deutsche Forschungsgemeinschaft, German research society). We thank ESA and DLR for providing SCIAMACHY spectra. The authors wish to thank the World Wide Lightning Location Network (http://wwlln.net), a collaboration among over 40 universities and institutions, for providing the lightning location data used in this paper. The v1.0 gridded satellite lightning data were produced by the NASA LIS/OTD Science Team (Principal Investigator, Hugh J. Christian, NASA/Marshall Space Flight Center) and are available from the Global Hydrology Resource Center (http://ghrc.msfc.nasa.gov). NASA is acknowledged for providing TRMM (http://mirador.gsfc.nasa.gov/) and LIS (http://thunder.nsstc.nasa.gov/data/) data. We thank the TEMIS team for providing SCIAMACHY cloud fractions (FRESCO+, http://www.temis.nl). We acknowledge NOAA Air Resources Laboratory for providing the HYSPLIT trajectory model (http://ready.arl.noaa.gov/HYSPLIT.php). MOPITT CO measurements are provided by NASA. SCIAMACHY Aerosol Absorbing Index data was provided by Marloes Penning de Vries. ATSR fire counts were taken from the World Fire Atlas from the Data User Element of the European Space Agency. We thank Craig Rodger, Bob Holzworth and Ken Pickering for helpful discussions, and two anonymous reviewers for their constructive comments during the open discussion process.

The service charges for this open access publication have been covered by the Max Planck Society.

Edited by: B. N. Duncan 


\section{References}

Abarca, S. F., Corbosiero, K. L., and Galarneau, T. J.: An evaluation of the Worldwide Lightning Location Network (WWLLN) using the National Lightning Detection Network (NLDN) as ground truth, J. Geophys. Res., 115(D18), D18206, doi:10.1029/2009JD013411, 2010.

Arnone, E., Kero, A., Dinelli, B. M., Enell, C. F., Arnold, N. F., Papandrea, E., Rodger, C. J., Carlotti, M., Ridolfi, M., and Turunen, E.: Seeking sprite-induced signatures in remotely sensed middle atmosphere $\mathrm{NO}_{2}$, Geophys. Res. Lett., 35, L05807, doi:10.1029/2007GL031791, 2008.

Beirle, S., Platt, U., Wenig, M., and Wagner, T.: $\mathrm{NO}_{\mathrm{x}}$ production by lightning estimated with GOME, Adv. Space Res., 34(4), 793797, 2004.

Beirle, S., Spichtinger, N., Stohl, A., Cummins, K. L., Turner, T., Boccippio, D., Cooper, O. R., Wenig, M., Grzegorski, M., Platt, U., and Wagner, T.: Estimating the $\mathrm{NO}_{\mathrm{x}}$ produced by lightning from GOME and NLDN data: a case study in the Gulf of Mexico, Atmos. Chem. Phys., 6, 1075-1089, doi:10.5194/acp-6-10752006, 2006.

Beirle, S., Salzmann, M., Lawrence, M. G., and Wagner, T.: Sensitivity of satellite observations for freshly produced lightning NOx, Atmos. Chem. Phys., 9, 1077-1094, doi:10.5194/acp-91077-2009, 2009.

Beirle, S., Kühl, S., Pukite, J., and Wagner, T.: Retrieval of tropospheric column densities of $\mathrm{NO}_{2}$ from combined SCIAMACHY nadir/limb measurements, Atmos. Meas. Tech., 3, 283299, doi:10.5194/amt-3-283-2010, 2010.

Bertram, T., Perring, A., Wooldridge, P., Crounse, J., Kwan, A., Wennberg, P., Scheuer, E., Dibb, J., Avery, M., Sachse, G., Vay, S., Crawford, J. H., McNaughton, C. S., Clarke, A., Pickering, K. E., Fuelberg, H., Huey, G., Blake, D. R., Singh, H. B., Hall, S. R., Shetter, R. E., Fried, A., Heikes, B. G., and Cohen, R. C.: Direct measurements of the convective recycling of the upper troposphere, Science, 315(5813), 816-820, doi:10.1126/science.1134548, 2007.

Boersma, K. F., Eskes, H. J., and Brinksma, E. J.: Error analysis for tropospheric $\mathrm{NO}_{2}$ retrieval from space, J. Geophys. Res., 109, D04311, doi:10.1029/2003JD003962, 2004.

Boersma, K. F., Eskes, H. J., Meijer, E. W., and Kelder, H. M.: Estimates of lightning $\mathrm{NO}_{\mathrm{x}}$ production from GOME satellite observations, Atmos. Chem. Phys., 5, 2311-2331, doi:10.5194/acp-52311-2005, 2005.

Bovensmann, H., Burrows, J. P., Buchwitz, M., Frerick, J., Noël, S., Rozanov, V. V., Chance, K. V., and Goede, A. P. H.: SCIAMACHY: Mission objectives and measurement modes, J. Atmos. Sci., 56(2), 127-150, 1999.

Bucsela, E. J., Pickering, K. E., Huntemann, T. L., Cohen, R. C., Perring, A., Gleason, J. F., Blakeslee, R. J., Albrecht, R. I., Holzworth, R., Cipriani, J. P., Vargas-Navarro, D., Mora-Segura, I., Pacheco-Hernández, A., and Laporte-Molina, S.: Lightninggenerated $\mathrm{NO}_{\mathrm{x}}$ seen by OMI during NASA's TC4 experiment, J. Geophys. Res., 115, D00J10, doi:10.1029/2009JD013118, 2010.

Cecil, D. J., Zipser, E. J., and Nesbitt, S. W.: Reflectivity, Ice Scattering, and Lightning Characteristics of Hurricane Eyewalls and Rainbands. Part I: Quantitative Description, Mon. Weather Rev., 130(4), 769-784, 2002.

Cecil, D. J.: Passive microwave brightness temperatures as proxies for hailstorms, J. Appl. Meteorol. Clim., 48(6), 1281-1286,
2009.

Christian, H. J., Blakeslee, R. J., Boccippio, D. J., Boeck, W. L., Buechler, D. E., Driscoll, K. T., Goodman, S. J., Hall, J. M., Koshak, W. J., Mach, D. M., and Stewart, M. F.: Global frequency and distribution of lightning as observed from space by the Optical Transient Detector, J. Geophys. Res., 108, 4005, doi:10.1029/2002JD002347, 2003.

Cooray, V., Rahman, M., and Rakov, V.: On the $\mathrm{NO}_{\mathrm{x}}$ production by laboratory electrical discharges and lightning, J. Atmos. Sol.Terr. Phy., 71(17-18), 1877-1889, 2009.

Del Genio, A. D., Yao, M.-S., and Jonas, J.: Will moist convection be stronger in a warmer climate?, Geophys. Res. Lett., 34, L16703, doi:10.1029/2007GL030525, 2007.

Dowden, R. L., Brundell, J. B., and Rodger, C. J.: VLF lightning location by time of group arrival (TOGA) at multiple sites, J. Atmos. Sol.-Terr. Phy., 64, 817-830, 2002.

Dowden, R. L., Holzworth, R. H., Rodger, C. J., Lichtenberger, J., Thomson, N. R., Jacobson, A. R., Lay, E., Blundell, J. B., Lyons, T. J., O'Keefe, S., Kawasaki, Z., Price, C., Prior, V., Ortega, P., Weinman, J., Mikhailov, Y., Veliz, O., Qie, X., Burns, G., Collier, A., Diaz, R., Adamo, C., Williams, E. R., Kumar, S., Raga, G. B., Rosado, J. M., Avila, E. E., Cliverd, M. A., Ulich, T., Gorham, P., Shanahan, T., Osipowicz, T., Cook, G., and Zhao, Y.: World-wide lightning location using VLF propagation in the Earth-Ionosphere waveguide, IEEE Antenn. Propag. M., 50(5), 40-60, 2008.

Dye, J. E., Ridley, B. A., Skamarock, W., Barth, M., Venticinque, M., Defer, E., Blanchet, P., Thery, C., Laroche, P., Baumann, K., Hubler, G., Parrish, D. D., Ryerson, T., Trainer, M., Frost, G., Holloway, J. S., Matejka, T., Bartels, D., Fehsenfeld, F. C., Tuck, A., Rutledge, S. A., Lang, T., Stith, J., and Zerr, R.: An overview of the stratospheric-tropospheric experiment: radiation, aerosols and ozone (STERAO)-deep convection experiment with result from the July 10, 1996 storm, J. Geophys. Res., 105, 10023-10045, 2000.

Hild, L., Richter, A., Rozanov, V., and Burrows, J. P.: Air mass calculations for GOME measurements of lightning-produced $\mathrm{NO}_{2}$, Adv. Space Res., 29(11), 1685-1690, 2002.

Hudman, R. C., Jacob, D. J., Turquety, S., Leibensperger, E. M., Murray, L. T., Wu, S., Gilliland, A. B., Avery, M., Bertram, T. H., Brune, W., Cohen, R. C, Dibb, J. E., Flocke, F. M., Fried, A., Holloway, J., Neuman, J. A., Orville, R., Perring, A., Ren, X.,Sachse, G. W., Singh, H. B., Swanson, A., and Wooldridge, P. J.: Surface and lightning sources of nitrogen oxides over the United States: Magnitudes, chemical evolution, and outflow, J. Geophys. Res., 112, D12S05, doi:10.1029/2006JD007912, 2007.

Huntrieser, H., Schumann, U., Schlager, H., Höller, H., Giez, A., Betz, H.-D., Brunner, D., Forster, C., Pinto Jr., O., and Calheiros, R.: Lightning activity in Brazilian thunderstorms during TROCCINOX: implications for NOx production, Atmos. Chem. Phys., 8, 921-953, doi:10.5194/acp-8-921-2008, 2008.

Huntrieser, H., Schlager, H., Lichtenstern, M., Roiger, A., Stock, P., Minikin, A., Höller, H., Schmidt, K., Betz, H.-D., Allen, G., Viciani, S., Ulanovsky, A., Ravegnani, F., and Brunner, D.: $\mathrm{NO}_{\mathrm{x}}$ production by lightning in Hector: first airborne measurements during SCOUT-O3/ACTIVE, Atmos. Chem. Phys., 9, 83778412, doi:10.5194/acp-9-8377-2009, 2009.

Jacobson, A., Holzworth, R., Harlin, J., Dowden, R., and Lay, E.: 
Performance assessment of the World Wide Lightning Location Network (WWLLN), using the Los Alamos Sferic Array (LASA) as ground truth, J. Atmos. Ocean. Technol., 23(8), 1082-1092, 2006.

Labrador, L. J., von Kuhlmann, R., and Lawrence, M. G.: The effects of lightning-produced $\mathrm{NO}_{\mathrm{x}}$ and its vertical distribution on atmospheric chemistry: sensitivity simulations with MATCHMPIC, Atmos. Chem. Phys., 5, 1815-1834, doi:10.5194/acp-51815-2005, 2005.

Langford, A. O., Portmann, R. W., Daniel, J. S., Miller, H. L., and Solomon, S.: Spectroscopic measurements of $\mathrm{NO}_{2}$ in a Colorado thunderstorm: Determination of the mean production by cloudto-ground lightning flashes, J. Geophys. Res., 109, D11304, doi:10.1029/2003JD004158, 2004.

Lay, E. H., Holzworth, R. H., Rodger, C. J., Thomas, J. N., Pinto Jr., O., and Dowden, R. L.: WWLL global lightning detection system: Regional validation study in Brazil, Geophys. Res. Lett., 31(3), L03102, doi:10.1029/2003GL018882, 2004.

Lay, E. H., Jacobson, A. R., Holzworth, R. H., Rodger, C. J., and Dowden, R. L.: Local time variation in land/ocean lightning flash density as measured by the World Wide Lightning Location Network, J. Geophys. Res., 112, D13111, doi:10.1029/2006JD007944, 2007.

LIS/OTD documentation: LIS/OTD Gridded Products V 2.2: 1995-2005, Documentation and Examples, 1 September 2006, http://ghrc.nsstc.nasa.gov/uso/ds_docs/lis_climatology/ lis_otd_gridded_products_documentation_v2.2.pdf, last access: March 2010, 2007.

Martin, R. V., Chance, K., Jacob, D. J., Kurosu, T. P., Spurr, R. J. D., Bucsela, E., Gleason, J. F., Palmer, P. I., Bey, I., Fiore, A. M., Li, Q., Yantosca, R. M., and Koelemeijer, R. B. A.: An improved retrieval of tropospheric nitrogen dioxide from GOME, J. Geophys. Res., 107(D20), 4437, doi:10.1029/2001JD001027, 2002.

Martin, R. V., Sauvage, B., Folkins, I., Sioris, C. E., Boone, C., Bernath, P., and Ziemke, J.: Space-based constraints on the production of nitric oxide by lightning, J. Geophys. Res., 112, D09309, doi:10.1029/2006JD007831, 2007.

Martin, R. V.: Satellite remote sensing of surface air quality, Atmos. Environ., 42, 7823-7843, 2008.

Ott, L. E., Pickering, K. E., Stenchikov, G. L., Allen, D. J., DeCaria, A. J., Ridley, B., Lin, R.-F., Lang, S., and Tao, W.$\mathrm{K}$.: Production of lightning $\mathrm{NO}_{\mathrm{x}}$ and its vertical distribution calculated from three-dimensional cloud-scale chemical transport model simulations, J. Geophys. Res., 115, D04301, doi:10.1029/2009JD011880, 2010.

Penning de Vries, M. J. M., Beirle, S., and Wagner, T.: UV Aerosol Indices from SCIAMACHY: introducing the SCattering Index (SCI), Atmos. Chem. Phys., 9, 9555-9567, doi:10.5194/acp-99555-2009, 2009.
Price, C. and Rind, D.: What determines the cloud-to-ground lightning fraction in thunderstorms?, Geophys. Res. Lett., 20, 463466, 1993.

Rahman, M., Cooray, V., Rakov, V. A., Uman, M. A., Liyanage, P., DeCarlo, B. A., Jerauld, J., and Olsen, R. C.: Measurements of $\mathrm{NO}_{\mathrm{x}}$ produced by rocket-triggered lightning, Geophys. Res. Lett., 34, L03816, doi:10.1029/2006GL027956, 2007.

Rodger, C. J., Brundell, J. B., Dowden, R. L., and Thomson, N. R.: Location accuracy of long distance VLF lightning locationnetwork, Ann. Geophys., 22, 747-758, doi:10.5194/angeo-22-7472004, 2004.

Rodger, C. J., Werner, S., Brundell, J. B., Lay, E. H., Thomson, N. R., Holzworth, R. H., and Dowden, R. L.: Detection efficiency of the VLF World-Wide Lightning Location Network (WWLLN): initial case study, Ann. Geophys., 24, 3197-3214, doi:10.5194/angeo-24-3197-2006, 2006.

Rodger, C. J., Brundell, J. B., Holzworth, R. H., and Lay, E. H.: Growing Detection Efficiency of the World Wide Lightning Location Network, Am. Inst. Phys. Conf. Proc., Coupling of thunderstorms and lightning discharges to near-Earth space: Proceedings of the Workshop, Corte (France), 23-27 June 2008, 1118, 15-20, doi:10.1063/1.3137706, 2009.

Scargle, J. D.: Publication bias: the file-drawer problem in scientific inference, J. Sci. Explor., 14(2), 94-106, 2000.

Schumann, U. and Huntrieser, H.: The global lightning-induced nitrogen oxides source, Atmos. Chem. Phys., 7, 3823-3907, doi:10.5194/acp-7-3823-2007, 2007.

Spencer, R. W., Goodman, H. M., and Hood, R. E.: Precipitation retrieval over land and ocean with the SSM/I: Identification and characteristics of the scattering signal, J. Atmos. Ocean. Tech., 6, 254-273, 1989.

Wagner, T., Beirle, S., Deutschmann, T., Eigemeier, E., Frankenberg, C., Grzegorski, M., Liu, C., Marbach, T., Platt, U., and Penning de Vries, M.: Monitoring of atmospheric trace gases, clouds, aerosols and surface properties from UV/vis/NIR satellite instruments, J. Opt. A, Pure Appl. Opt., 10, 104019, doi:10.1088/1464-4258/10/10/104019, 2008.

Wang, Y., DeSilva, A. W., Goldenbaum, G. C., and Dickerson, R. R.: Nitric oxide production by simulated lightning: Dependence on current, energy, and pressure, J. Geophys. Res., 103, 19149-19159, 1998.

Wang, P., Stammes, P., van der A, R., Pinardi, G., and van Roozendael, M.: FRESCO+: an improved $\mathrm{O}_{2}$ A-band cloud retrieval algorithm for tropospheric trace gas retrievals, Atmos. Chem. Phys., 8, 6565-6576, doi:10.5194/acp-8-6565-2008, 2008.

Zipser, E. J., Cecil, D. J., Liu, C., Nesbitt, S. W., and Yorty, D. P.: Where are the most intense thunderstorms on Earth?, B. Amer. Meteorol. Soc., 87, 1057-1071, 2006. 